\title{
The Role of Interstitial Fluid Pressurization in Articular Cartilage Lubrication
}

\author{
Gerard A. Ateshian \\ Departments of Mechanical Engineering and Biomedical Engineering, Columbia University, New \\ York, NY, USA
}

\begin{abstract}
Over the last two decades, considerable progress has been reported in the field of cartilage mechanics that impacts our understanding of the role of interstitial fluid pressurization on cartilage lubrication. Theoretical and experimental studies have demonstrated that the interstitial fluid of cartilage pressurizes considerably under loading, potentially supporting most of the applied load under various transient or steady-state conditions. The fraction of the total load supported by fluid pressurization has been called the fluid load support. Experimental studies have demonstrated that the friction coefficient of cartilage correlates negatively with this variable, achieving remarkably low values when the fluid load support is greatest. A theoretical framework that embodies this relationship has been validated against experiments, predicting and explaining various outcomes, and demonstrating that a low friction coefficient can be maintained for prolonged loading durations under normal physiological function. This paper reviews salient aspects of this topic, as well as its implications for improving our understanding of boundary lubrication by molecular species in synovial fluid and the cartilage superficial zone. Effects of cartilage degeneration on its frictional response are also reviewed.
\end{abstract}

\section{Introduction}

Articular cartilage is the bearing material of diarthrodial joints. Its primary function is to support and redistribute joint contact forces, and to reduce friction and wear. This function is closely dependent on the structure of this connective soft tissue, as reviewed in this paper. Interest in cartilage lubrication can be traced back to the early part of the twentieth century (Jones, 1936; Macconaill, 1932) and a review of the earlier cartilage lubrication literature can be found in a recent textbook chapter (Ateshian and Mow, 2005) as well as other review articles (Katta et al., 2008; Sah, 2009; Unsworth, 1991; Wright and Dowson, 1976). The low friction and wear of articular layers has been attributed to mixed modes of lubrication which include fluid film lubrication by synovial fluid (Dowson et al., 1969; Macconaill, 1932), boundary lubrication by a variety of candidate molecules in synovial fluid and cartilage (Charnley, 1960; Hills, 1989; Jay et al., 2001; McCutchen, 1966; Radin et al., 1970; Schmidt et al., 2007; Swann and Radin, 1972; Walker et al., 1968), and lubrication by pressurization of the interstitial fluid of cartilage (Forster and Fisher, 1996; Krishnan et al., 2004b; Lewis and McCutchen, 1959; McCutchen, 1962).

\footnotetext{
(C) 2009 Elsevier Ltd. All rights reserved.
}

Publisher's Disclaimer: This is a PDF file of an unedited manuscript that has been accepted for publication. As a service to our customers we are providing this early version of the manuscript. The manuscript will undergo copyediting, typesetting, and review of the resulting proof before it is published in its final citable form. Please note that during the production process errors may be discovered which could affect the content, and all legal disclaimers that apply to the journal pertain. 
The science of lubrication, or tribology, is rooted in mechanics and surface chemistry. Several of the modes of lubrication hypothesized to prevail in articular joints can be modeled mathematically and the predictions of these models may be compared to experiments in a process that can support or reject specific hypotheses. This paper reviews recent findings related to the role of interstitial fluid pressurization in cartilage lubrication, summarizing major new insights, gained from theoretical predictions and experimental validations, that support this mode of lubrication.

\section{Why Not Fluid Film Lubrication?}

A standard mode of lubrication familiar to engineers is fluid film lubrication, where a lubricant forms a thin layer that separates the bearing surfaces (Hamrock, 1994). The fluid in this layer is pressurized and is able to support the load transmitted across the bearing surfaces, avoiding direct contact between them, thereby minimizing friction and wear. The pressurization of this fluid occurs either as a result of the relative velocity of the bearing surfaces (hydrodynamic and squeeze film lubrication) or as a result of pumping of the lubricant into the space between the surfaces (hydrostatic lubrication). The film thickness is typically on the order of a micron or less. For example, this mode of lubrication prevails in automotive applications, such as the bearings supporting the crankshaft of a piston engine, or at the interface between cam and follower.

Fluid film lubrication had long been considered a likely mode of lubrication for articular cartilage because the viscous synovial fluid found in diarthrodial joints appeared to be well suited as a fluid film lubricant (Dowson et al., 1969; Macconaill, 1932). In principle, the validity of this lubrication mechanism may be tested either directly, by measuring the presence and thickness of the lubricant film, or indirectly, by analyzing the frictional response over a range of load magnitudes, sliding velocities, and lubricant viscosities, and comparing the outcome to theoretical predictions. In the case of articular cartilage, it has not been possible to measure the film thickness directly, because standard methods employ highly polished transparent bearing surfaces, relying on Newton fringes to detect the distance between them; cartilage is too opaque and insufficiently smooth to allow this type of measurement.

Theoretical predictions have depended on the level of modeling detail ascribed to the cartilage and synovial fluid lubricant. A review of the related literature is beyond the scope of this article but may be found elsewhere (Ateshian and Mow, 2005). Briefly, it appears that there are no studies in the literature that demonstrate direct agreement between theoretical predictions from fluid film lubrication and experimental measurements of friction. On the contrary, a recent detailed study has shown that experimental cartilage friction measurements do not support this mode of lubrication, based on the concept of Stribeck curves which predict a specific relationship between the friction coefficient and the non-dimensional Hersey number over a range of lubrication regimes (Gleghorn and Bonassar, 2008). This recent finding complements some of the earlier arguments presented in the literature against this mode of lubrication (Charnley, 1960; McCutchen, 1962).

A likely explanation for this observation has been provided from theory, when accounting for the porous nature of articular cartilage. In a series of increasingly sophisticated theoretical analyses, Hlavacek has shown that a fluid film gets depleted within a fraction of a second when porous deformable bearing surfaces are brought into contact (Hlavacek, 1993a; Hlavacek, 1993b; Hlavacek, 1995; Hlavacek, 1999; Hlavacek, 2000; Hlavacek, 2001; Hlavacek and Novak, 1995), because the pressurized fluid can filtrate into the porous cartilage layers. Thus, unlike traditional fluid film lubrication between impermeable bearing surfaces, where the escape path for the pressurized fluid film depends on the characteristic dimension of the apparent contact area, lubrication between cartilage surfaces provides a very short escape path for the lubricant. 


\section{Self-Pressurized Hydrostatic and Weeping Bearings}

Starting in the late 1950's, McCutchen and co-workers proposed an explanation for the mechanism of lubrication in articular cartilage which is related to the concept of hydrostatic lubrication (Lewis and McCutchen, 1959; McCutchen, 1959; McCutchen, 1962; McCutchen, 1983). McCutchen demonstrated experimentally that the friction coefficient of cartilage against glass rises over time under a constant applied load (McCutchen, 1962); when the load is temporarily removed for $1 \mathrm{~s}$, then reapplied, the friction coefficient does not return to its lowest initial value, dropping only slightly before rising again under the applied load. These observations guided him in the formulation of his proposed lubrication mechanism.

According to this mechanism, pressing two articular layers together pressurizes the cartilage pore (interstitial) fluid, and this pressurized fluid supports most of the applied load, leaving only a small fraction to be supported by the solid matrix. The implication of this load sharing mechanism is that frictional forces would be significant only over the portion of the load transferred across the solid matrices of the opposing articular layers; thus, as long as the interstitial fluid pressure remains elevated, supporting most of the load, the friction should remain low. As the fluid pressure subsides over time and load sharing shifts progressively more to the opposing solid matrices, the friction should rise accordingly, as indeed observed in his experiments. On this basis, this proposed mechanism was described as that of a self-pressurized hydrostatic bearing.

To further explain the low values of the friction coefficient observed upon initial load application, McCutchen proposed that the pressurized fluid in the cartilage pores flows out into the space between the contacting surfaces, forming "...a thick film of lubricant, where 'weeping' through the porous wall supplies enough liquid to maintain the film" (McCutchen, 1959).

This self-pressurized hydrostatic and weeping lubrication mechanism offered an attractive alternative to the classical modes of hydrodynamic or elastohydrodynamic lubrication because it proposed a straightforward explanation for the time-dependent rise of the cartilage friction coefficient observed in experiments. Furthermore, by showing that the friction coefficient of cartilage against glass did not return to its initial low value when cartilage was unloaded for 1 $\mathrm{s}$, McCutchen discounted the mechanism of squeeze-film lubrication on the basis that unloading the cartilage and separating it temporarily from the opposing glass surface should have allowed sufficient time for a squeeze film to be replenished.

Nevertheless, his proposed mechanism generated controversy with proponents of fluid film lubrication, most notably the renowned tribologist Duncan Dowson and his co-workers (Dowson, 1973; Dowson et al., 1969; Walker et al., 1969), who argued that his hypothesized weeping mechanism violated the axiom of conservation of linear momentum. In fact several investigators proposed that, contrary to McCutchen's weeping hypothesis, the synovial fluid trapped between the cartilage surfaces would undergo ultrafiltration whereby its water solvent and small molecular weight solutes would flow into the porous cartilage, leaving behind a hyaluronic acid gel that might act as a boundary lubricant (Longfield et al., 1969; Maroudas, 1967; Walker et al., 1968; Walker et al., 1970). This alternative mechanism was called 'boosted lubrication' (Longfield et al., 1969; Walker et al., 1968).

When this controversy arose in the 1960s, theoretical and computational modeling tools were insufficiently developed to address the feasibility of weeping flow or boosted lubrication between two bearing surfaces, where at least one of the bearing surfaces is porous and deformable. As the application of porous media theories to articular cartilage became more widespread, and with the formulation of more elaborate frameworks for modeling cartilage and synovial fluid, theoretical and computational predictions have mostly supported the 
hypothesis that the fluid between the bearing surfaces will flow into the cartilage, particularly in the central region of the contact (Hlavacek, 1993b; Hlavacek, 1995; Hlavacek, 1999; Hlavacek, 2000; Hlavacek and Novak, 1995; Hou et al., 1989; Soltz et al., 2003), though one computational study has been supportive of the weeping mechanism (Macirowski et al., 1994).

However, these disparate hypotheses and predictions on the direction of fluid flow have somewhat obscured the other relevant aspect of McCutchen's proposed lubrication mechanism, namely the role of interstitial fluid load support in the lubrication of cartilage, and its regulation of the temporal response of the friction coefficient. Starting from the late 1970s, porous media models of cartilage were formulated which could be used to predict interstitial fluid pressurization from theory. These models were significantly refined over the following decades, and starting in the 1990s, experimental measurements of interstitial fluid pressure were shown to agree with these theoretical frameworks. Investigators focused again on the potential tribological role of this interstitial fluid load support, irrespective of the direction of fluid flow at the articular surface, armed with these validated theoretical and experimental tools. Prior to reviewing the salient findings on this topic, we start by summarizing the cartilage structure and composition, and salient aspects of cartilage mechanics.

\section{Cartilage Structure and Composition}

Articular cartilage is a soft connective tissue consisting primarily of water (68 to $85 \%$ by weight), a fibrillar matrix of type II collagen (10 to 20\%), large aggregating proteoglycans (aggrecans, 5 to 10\%), and chondrocytes (Mow and Ratcliffe, 1997). The articular layer exhibits compositional heterogeneity from the surface to the subchondral bone; it is typically divided into three regions commonly called the superficial, middle and deep zones (SZ, MZ and DZ, respectively) (Maroudas, 1979; Mow and Ratcliffe, 1997). The delineation between these zones is often determined on the basis of the orientation of the collagen fibrils, which may be determined via polarized light microscopy (PLM), magnetic resonance imaging (MRI), or Fourier Transform infra-red imaging (FTIRI) (Bi et al., 2005; Nieminen et al., 2001; Nissi et al., 2006; Xia et al., 2007; Xie et al., 2008).

In the superficial zone, collagen fibrils are predominantly oriented in the plane tangent to the articular surface, whereas in the deep zone they are mostly perpendicular to the subchondral surface; the fibril orientation transitions between these two predominant directions over the span of the middle zone, following a pattern variably described as random or arch-like. The collagen content is highest at the articular surface and decreases toward the deep zone. If the surface of cartilage is punctured with a needle, the resulting hole assumes the form of a slit whose orientation, called the split line direction, generally follows a consistent pattern over the articular surface. It is believed that the split line direction represents a preferred orientation of the collagen fibrils in the plane tangent to the articular surface (Mow and Ratcliffe, 1997).

In contrast to collagen, the proteoglycan (PG) content is lowest at the articular surface, rises in the middle zone, then remains constant or decreases slightly in the deep zone (Maroudas, 1979). Proteoglycans are generally considered enmeshed within, and bound to the collagen matrix; therefore, the collagen, PG, and chondrocytes together form the solid matrix of the tissue. The interstitial fluid content, or cartilage porosity, is highest in the SZ and decreases in the MZ and DZ (Torzilli et al., 1990). The interstitial fluid consists of water and small electrolytes, primarily $\mathrm{Na}^{+}$and $\mathrm{Cl}^{-}$. Most of the interstitial fluid is free to flow within the porous solid matrix. 


\section{Cartilage Mechanics}

Based on experimental studies of articular cartilage mechanics, it is well recognized that this tissue exhibits a range of complex characteristics and behaviors. Cartilage exhibits flowdependent viscoelasticity, which represents the energy dissipation mechanism resulting from the frictional interactions between the interstitial fluid and the solid matrix (Mow et al., 1980; Zarek and Edward, 1963). It exhibits flow-independent viscoelasticity, which represents energy dissipation mechanisms intrinsic to the various constituents of the solid matrix (Hayes and Bodine, 1978; Mak, 1986); intrinsic viscoelasticity results from the formation and breaking of temporary bonds between molecules.

Because of the fibrillar nature of the collagen matrix, and since fibrils can resist tensile loads much better than compressive loads, cartilage exhibits a much higher stiffness in tension than compression (Kempson, 1979; Mow and Ratcliffe, 1997), a phenomenon that has been called tension-compression nonlinearity (Soltz and Ateshian, 2000a). Furthermore, since collagen fibrils exhibit preferred orientations, the tissue exhibits anisotropy in tension (Kempson, 1979; Mow and Ratcliffe, 1997) and compression (Chahine et al., 2004).

Proteoglycans contain large amounts of glycosaminoglycans (GAG), particularly chondroitin sulfate (CS) and keratan sulfate (KS), that carry negative electrical charges in solution (Maroudas, 1979). Because these charges are held by PGs enmeshed within the solid matrix, the total number of electrical charges, typically normalized by the volume of interstitial fluid, is called the fixed charge density (FCD). Due to the presence of these charges, several additional physicochemical phenomena characterize the behavior of articular cartilage. By attracting more cations than anions into the tissue to maintain electroneutrality, a net imbalance in electrolyte concentration is created between the cartilage interstitial fluid and the surrounding tissue bath; this imbalance produces an osmotic pressure difference whereby the interstitial fluid exhibits a higher pressure than the external solution. Because this osmotic pressure difference arises specifically from charge effects, it is called the Donnan osmotic pressure (Overbeek, 1956). This osmotic pressure swells the solid matrix of the tissue and is resisted by the resulting solid matrix tensile stress (Maroudas, 1976). Other electrical phenomena associated with the FCD include streaming and diffusion potentials and currents, resulting from the flow of ions past the fixed negative charges (Frank et al., 1987; Frank et al., 1990; Lai et al., 1991; Lai et al., 2000).

Because of the heterogeneous composition of cartilage, the mechano-electrochemical phenomena described above exhibit variable properties through the depth of the articular layer.

\section{Interstitial Fluid Pressurization}

\section{Theoretical Predictions}

In addition to the Donnan osmotic pressure arising from physicochemical effects, the interstitial fluid of cartilage will pressurize as a result of mechanical loading of the tissue. Even in the absence of direct experimental evidence, this pressurization was hypothesized to occur because of the hydrated nature of the tissue and the ability of its interstitial fluid to flow through the pores (McCutchen, 1962; Zarek and Edward, 1963). The ability to predict the pressurization and flow of this interstitial fluid from theory was considerably advanced with the application of porous media theories to the analysis of cartilage mechanics, most notably, the biphasic theory for articular cartilage (Mow et al., 1980). The earliest theoretical predictions using this framework were primarily concerned with the analysis of canonical configurations relevant to material testing, such as confined compression (Mow et al., 1980), unconfined compression (Armstrong et al., 1984), and indentation (Mak et al., 1987). Subsequent theoretical studies also addressed the analysis of contact involving biphasic articular layers (Ateshian et al., 
1994; Ateshian and Wang, 1995). With the formulation of finite element frameworks (Almeida and Spilker, 1997; Spilker et al., 1992; Spilker and Suh, 1990; Suh et al., 1991; Wayne et al., 1991) and the subsequent availability of commercial finite element codes (Wu et al., 1998), the application of porous media theories for predicting interstitial fluid pressure and flow has become more widespread.

\section{Experimental Measurements}

Several experimental measurements of interstitial fluid pressurization in articular cartilage have been reported in confined and unconfined compression (Oloyede and Broom, 1991; Park et al., 2003; Soltz and Ateshian, 1998; Soltz and Ateshian, 2000b). In confined compression, where a cylindrical cartilage plug is loaded in a confining chamber of the same diameter using a free-draining porous indenter, the interstitial fluid pressure has been measured on the circular specimen face abutting the bottom impermeable wall of the chamber. In a creep test, upon application of a constant load, the pressure was observed to rapidly rise to a value equal to the applied compressive stress, before slowly subsiding back to zero at a rate comparable to that of the creep deformation (Fig. 1). Since the fluid pressure is equal to the applied stress upon initial load application (Fig. 1b), whereas the creep deformation is zero (Fig. 1a), it is possible to conclude that all of the applied load is initially supported by the pressurized interstitial fluid, and none by solid matrix deformation. As time progresses however, the pressurized interstitial fluid flows out of the tissue, through the porous indenter, leading to a progressive reduction in fluid pressure and increase in solid matrix deformation. Thus, over time, the load becomes progressively more supported by the solid matrix. This concept of load sharing between the solid and fluid matrix (Ateshian and Wang, 1995; Macirowski et al., 1994; McCutchen, 1959; Oloyede and Broom, 1993; Oloyede and Broom, 1996), which may be called the interstitial fluid load support, plays an important role in the frictional response of articular cartilage.

Comparisons of experimental measurements with theoretical predictions from the biphasic theory have shown very good agreement in confined compression creep, stress-relaxation, and dynamic loading (Soltz and Ateshian, 1998; Soltz and Ateshian, 2000b), providing confidence in the predictive ability of the biphasic theory for this testing configuration (Fig. 1). Good agreement between theory and experiment also lends confidence in the physical interpretation of observed phenomena using the context of that theoretical framework. Thus, according to the biphasic theory, the reason that the interstitial fluid load support initially matches $100 \%$ of the applied stress in confined compression occurs because the solid and fluid constituents of articular cartilage are nearly incompressible (in the range of pressures encountered in diarthrodial joints, typically less than $20 \mathrm{MPa}$ ). Since interstitial fluid cannot escape from cartilage instantaneously, the cartilage specimen must maintain its volume immediately following the application of a step load. In confined compression the specimen is surrounded by rigid walls; thus, an isochoric (volume-conserving) deformation cannot occur, implying that the only manner by which the tissue can resist the applied load is via interstitial fluid pressurization.

In unconfined compression, it was found that good agreement between theoretical predictions and experimental measurements of the load response (Cohen et al., 1998; Soulhat et al., 1999) and interstitial fluid pressurization (Park et al., 2003; Soltz and Ateshian, 2000a) could be achieved only after incorporating tension-compression nonlinearity in the modeling of the solid matrix of cartilage. For example, the peak interstitial fluid load support was measured to be as high as $99 \%$ in some cartilage specimens (Park et al., 2003), whereas theory could only predict a peak value of $33 \%$ when using the classical framework where tensile and compressive properties are assumed identical. In contrast, when accounting for tension-compression 
nonlinearity, theory could predict a fluid load support approaching $100 \%$ as the ratio of the tensile to compressive moduli increases far in excess of unity (Soltz and Ateshian, 2000a).

This finding provided a remarkable new insight into the structure-function relationship of articular cartilage: Though cartilage is primarily loaded in compression under physiological articular contact, it is now understood that the axial compression of the tissue is resisted by the high tensile modulus which prevents significant expansion in the directions transverse to the loading axis. In effect, the high tensile stiffness acts to resist lateral expansion in a manner similar to the rigid side-wall of a confining chamber; thus, even in unconfined compression, the interstitial fluid must pressurize considerably to support most of the applied compressive stress.

This observation considerably clarifies the functional role of collagen in articular cartilage, whose structure is best suited to resist tension, even though cartilage is normally subjected to compression. Since collagen is oriented parallel to the articular surface in the superficial zone, this ultrastructural organization appears to be optimized to provide the greatest amount of interstitial fluid load support at the articular surface, as confirmed experimentally in a comparison of interstitial fluid load support at the articular surface versus the deep zone (Park et al., 2003). In that study, the authors demonstrated that the fluid load support was $94 \pm 4 \%$ at the articular surface, but only $71 \pm 8 \%$ at the deep zone of immature bovine articular cartilage.

Despite the successes of many of these reported experiments, measurements of the interstitial fluid pressure of cartilage are subject to practical limitations, most notably the mechanical impedance of the pressure transducer. All transducers measure pressure via the deformation of a sensing surface, such as a diaphragm instrumented with a strain gauge, or a piezoresistive material. This deformation can occur only as a result of fluid displacement into the transducer chamber, thus requiring a finite amount of fluid to flow out of cartilage and into the transducer before a pressure rise is detected (Park et al., 2003). The resulting delay in the rise of the pressure following load application seemingly contradicts the theoretical prediction that pressure should increase immediately upon loading, potentially leading to an erroneous interpretation of the results. However, it should be appreciated that such delays are artifacts of the measurement method, and not a reflection of a fundamental mechanism in cartilage.

\section{Cartilage Lubrication by Interstitial Fluid Load Support}

\section{Temporal Variation in the Friction Coefficient}

McCutchen's early study (McCutchen, 1962) provided direct evidence of the temporal increase of the friction coefficient under constant loading. More extensive experimental results were subsequently reported in a doctoral dissertation by Malcolm (Malcom, 1976), who measured the frictional response of cartilage against cartilage, using bovine shoulder joints. Malcolm investigated a variety of testing conditions, including variations in the magnitude and temporal profile of the applied load, the sliding velocity, and the role of synovial fluid versus saline as a lubricant. Based on his experimental observations, he proposed that the response of cartilage could be attributed to the biphasic nature of cartilage. Unfortunately, these results were not disseminated in the peer-reviewed literature due to the author's untimely demise.

A similarly extensive series of cartilage friction experiments were subsequently reported by Forster and Fisher (Fig. 2) and these authors also attributed their observations to the biphasic nature of this tissue (Forster and Fisher, 1996;Forster and Fisher, 1999). In the interpretation of their experimental results, they specifically proposed that the friction force at the articular surface was proportional to the load carried by the solid phase. 


\section{Theoretical Model for Load Sharing}

A challenge in formulating a theoretical model for the frictional response of cartilage in a framework that accounts for interstitial fluid pressurization lies in the formulation of load sharing between the solid and fluid constituents at the contact interface. What should be the precise expression for the load supported by the solid? Porous media theories have proposed different ways of splitting the stresses between the solid matrix and the interstitial fluid. For example, in the biphasic theory (Mow et al., 1980), which is based on the theory of mixtures of intrinsically incompressible constituents (Bowen, 1976; Bowen, 1980; Truesdell and Toupin, 1960), the Cauchy stress tensor in the mixture may be split into the solid and fluid stresses,

$$
\begin{aligned}
& \mathbf{T}^{s}=-\varphi^{s} p \mathbf{I}+\mathbf{T}^{e} \\
& \mathbf{T}^{f}=-\varphi^{f} p \mathbf{I}
\end{aligned}
$$

where $p$ is the interstitial fluid pressure, $\mathbf{T}^{e}$ is the effective stress resulting from strains in the solid matrix, $\varphi^{s}$ is the volume fraction of the solid constituent, and $\varphi^{f}$ is the volume fraction of the fluid constituent, satisfying $\varphi^{s}+\varphi^{f}=1$; I is the identity tensor. In mixture theory, the stresses $\mathbf{T}^{\alpha}$ are called apparent stresses, since they represent a measure of the force acting on constituent $\alpha$ per unit area of the mixture. In contrast, the fluid pressure $p$ is a conventional measure of stress, representing a measure of the force acting on the fluid per unit area of the fluid. Splitting the stresses as shown in Eq.(1) embodies the fact that the intrinsically incompressible constituents bear a fraction of the hydrostatic fluid pressure in proportion to their respective volume fractions.

Note that the expression for the fluid stress is specialized to the case where the explicit manifestation of fluid viscosity is neglected, a specialization that has implications for the frictional response as addressed below. (In cartilage, the fluid viscosity has a greater influence on the permeation of the interstitial fluid through the porous matrix, a mechanism not neglected in this framework.)

The mixture stress is given as the sum of the solid and fluid stresses, $\mathbf{T}=\mathbf{T}^{s}+\mathbf{T}^{f}$, or equivalently,

$$
\mathbf{T}=-p \mathbf{I}+\mathbf{T}^{e}
$$

For any stress $\mathbf{T}^{\alpha}$, its contribution to the contact force acting on a contact interface $\Gamma$ whose unit outward normal is $\mathbf{n}$ is obtained by integrating the corresponding traction vector $\mathbf{t}^{\alpha}=\mathbf{T}^{\alpha}$ - $\mathbf{n}$ over that interface,

$$
\mathbf{f}^{\alpha}=\int_{\Gamma} \mathbf{t}^{\alpha} d \Gamma
$$

Integrating the component of $\mathbf{t}^{\alpha}$ normal to the interface yields its contribution to the contact force,

$$
\mathbf{f}_{n}^{\alpha}=\int_{\Gamma}(\mathbf{n} \otimes \mathbf{n}) \cdot \mathbf{t}^{\alpha} d \Gamma
$$

where $\otimes$ denotes the dyadic product of vectors, whereas the tangential component yields the contribution to the friction force, 


$$
\mathbf{f}_{t}^{\alpha}=\int_{\Gamma}(\mathbf{I}-\mathbf{n} \otimes \mathbf{n}) \cdot \mathbf{t}^{\alpha} d \Gamma
$$

The magnitude of $\mathbf{f}_{n}^{\alpha}$ is denoted by $\left|\mathbf{f}_{n}^{\alpha}\right|$ and the magnitude of $\mathbf{f}_{t}^{\alpha}$ by $\left|\mathbf{f}_{t}^{\alpha}\right|$. The total contact force is obtained from the mixture stress $\mathbf{T}$ to produce the normal $\operatorname{load} \mathbf{f}_{n}$ and the friction force $\mathbf{f}_{t}$. By definition, the friction coefficient is effectively given as

$$
\mu_{\mathrm{eff}}=\left|\mathbf{f}_{t}\right| /\left|\mathbf{f}_{n}\right|
$$

The basic premise of a cartilage friction model that ascribes the temporal response of $\mu_{\text {eff }}$ to the time-varying interstitial fluid load support is that the friction force magnitude $\left|\mathbf{f}_{t}\right|$ is proportional to the load supported by the solid matrix (Ateshian, 1997; Forster and Fisher, 1996; McCutchen, 1959).

It would seem natural to assume that this load component is $\mathbf{f}_{n}^{s}$, evaluated using $\mathbf{t}^{s}=\mathbf{T}^{s} \bullet \mathbf{n}$ in Eq.(4). However this reasoning would be mistaken because, according to Newton's third law of motion, the friction force acting on one of the contacting surfaces must be equal and opposite to that acting on the other surface. Thus, the friction force must be related to a traction component that has equal magnitude across the contact interface. According to mixture theory, the traction components that are continuous across a biphasic interface are $\mathbf{t}=\mathbf{T} \cdot \mathbf{n}$ and $\mathbf{t}^{p}=-$ $p \mathbf{n}$ (and thus $\mathbf{t}^{e}=\mathbf{T}^{e} \cdot \mathbf{n}$ ) (Ateshian et al., 1994;Hou et al., 1989); in general, $\mathbf{t}^{s}$ is not continuous because the value of $\varphi^{s}$ need not be the same on the two opposing cartilage layers. $\mathbf{t}$ represents the total traction on the mixture (the sum of forces acting on all mixture constituents on a surface with unit outward normal $\mathbf{n}$, divided by the area of all constituents); $\mathbf{t}^{p}$ represents the true traction on the interstitial fluid (the force acting on the fluid per unit area of the fluid).

Therefore, in a first embodiment of a cartilage biphasic friction model, it was proposed that the portion of the normal load supported by the solid is $\mathbf{f}_{n}^{e}$, evaluated from $\mathbf{t}^{e}$ using Eq.(4). Physically, $\mathbf{f}_{n}^{e}$ represents the force resisted by the deformation (strain) of the solid matrix; the remainder of the contact load is provided by the contribution from interstitial fluid pressure, $\mathbf{f}_{n}=\mathbf{f}_{n}^{p}+\mathbf{f}_{n}^{e}$. Then, the friction force is assumed to be given by Amonton's law, $\left|\mathbf{f}_{t}\right|=\mu_{e q} \mid \mathbf{f}_{n}^{e}$, such that the friction coefficient reduces to $\mu_{\text {eff }}=\mu_{e q}\left|\mathbf{f}_{n}^{e}\right| /\left|\mathbf{f}_{n}\right|$ (Ateshian, 1997). In this model, $\mu_{e q}$ represents the friction coefficient achieved when the interstitial fluid pressure has subsided $\left(\mathbf{f}_{n}=\mathbf{f}_{n}^{e}\right)$.

In this theoretical study, it was shown that this model could predict the temporal increase of the friction coefficient under a constant applied load; furthermore, this model could qualitatively predict McCutchen's experimental observation that temporary load removal does not return the friction coefficient to its initial value (Ateshian, 1997). Since the fluid viscosity is neglected in this formulation, this model predicts that the friction coefficient is zero when the entire contact load is supported by interstitial fluid pressurization. However, this friction model does not depend on the actual value of the porosity of cartilage, only on the fact that the tissue is porous, representing a significant limitation. Thus, the model is unable to distinguish between a bearing material whose porosity is $85 \%$ versus one whose porosity is $1 \%$, predicting an equally small friction coefficient when most of the load is supported by interstitial fluid pressurization.

In a subsequent study where this theoretical model was compared directly to measurements of the friction coefficient of cartilage against a rigid impermeable surface, under the loading configuration of confined compression stress-relaxation, it was concluded that the model needed to be modified to properly predict the friction force (Ateshian et al., 1998). A revised 
measure of the load supported by the solid matrices at the contact interface was given by $\mathbf{f}^{s s}$ evaluated from Eq.(3) using

$$
\mathbf{t}^{s s}=\left(-\varphi p \mathbf{I}+\mathbf{T}^{e}\right) \cdot \mathbf{n}=\varphi \mathbf{t}^{p}+\mathbf{t}^{e}
$$

where $\varphi$ is the fraction of the (apparent) contact area where the solid matrix of one of the bearing surfaces is contacting the solid matrix of the opposing bearing surface $(0 \leq \varphi \leq 1)$. The traction vector $\mathbf{t}^{s s}$ is continuous across the contact interface, since $\mathbf{t}^{p}$ and $\mathbf{t}^{e}$ both satisfy the continuity requirement and $\varphi$ is a scalar value representative of the interface. According to this revised measure, the normal component $\mathbf{f}_{n}^{s s}=\varphi \mathbf{f}_{n}^{p}+\mathbf{f}_{n}^{e}$ represents the portion of the total contact load, $\mathbf{f}_{n}=\mathbf{f}_{n}^{p}+\mathbf{f}_{n}^{e}$, which is supported by the solid matrices, taking into account the force contributed by the solid matrix deformation, $\mathbf{f}_{n}^{e}$, as well as the fraction of the hydrostatic stress supported by the contacting solid matrices, $\varphi \mathbf{f}_{n}^{p}$. It follows that the portion of the contact force supported by fluid-fluid and fluid-solid interactions is $\mathbf{f}_{n}-\mathbf{f}_{n}^{s s}=(1-\varphi) \mathbf{f}_{n}^{p}$.

If the contacting surfaces are porous but (hypothetically) smooth, a simple probability analysis shows that $\varphi=\varphi_{+}^{s} \varphi_{-}^{s}$ where $\varphi_{+}^{s}$ and $\varphi_{-}^{s}$ represent the solid volume fraction of the two opposing bearing surfaces ${ }^{1}$. For example, if the two surfaces have porosities of $80 \%\left(\varphi_{+}^{s}=\varphi_{-}^{s}=0.2\right.$ and $\varphi_{+}^{f}=\varphi_{-}^{f}=0.8$ ), then $\varphi=0.2 \times 0.2=0.04$, implying that solid matrices are in direct contact over only $4 \%$ of the apparent contact area. Over the remainder of the contact area, the solid matrix of one surface is in contact with the fluid of the opposing surface

$\varphi_{+}^{s} \varphi_{-}^{f}=\varphi_{-}^{s} \varphi_{+}^{f}=0.2 \times 0.8=0.16$, for a total of $32 \%$ of the contact area) or fluid is in contact with fluid $\left(\varphi_{+}^{f} \varphi_{-}^{f}=0.8 \times 0.8=0.64\right.$, or $64 \%$ of the contact area).

If the porous surfaces are non-smooth and contact initiates at asperities, temporarily trapping fluid between the bearing surfaces, the value of $\varphi$ may be temporarily smaller than $\varphi_{+}^{s} \varphi_{-}^{s}$, until the asperities flatten under the applied load and the trapped fluid escapes via squeeze-film action or flow into the porous cartilage (Soltz et al., 2003).

According to this revised formulation, the friction arises only from the solid-to-solid interactions, on the assumption that the fluid viscosity contributes negligibly to the frictional response, so that

$$
\begin{aligned}
& \left|\mathbf{f}_{t}\right|=\mu_{e q} \mid \frac{\mathbf{f}_{n}^{s s} \mid}{} \\
& \mu_{\text {eff }}=\mu_{e q} \frac{\left|\varphi \mathbf{f}_{n}^{p}+\mathbf{f}_{n}^{e}\right|}{\left|\mathbf{f}_{n}^{p}+\mathbf{f}_{n}^{e}\right|}=\mu_{e q} \frac{\left|\mathbf{f}_{n}-(1-\varphi) \mathbf{f}_{n}^{p}\right|}{\left|\mathbf{f}_{n}\right|}
\end{aligned}
$$

When the interstitial fluid pressure has subsided $\left(\mathbf{f}_{n}^{p}=\mathbf{0}\right)$, all of the contact load is supported by the opposing solid matrices, $\mathbf{f}_{n}^{s s}=\mathbf{f}_{w}$, and the friction coefficient achieves its equilibrium value, $\mu_{e f f}=\mu_{e q}$. In the opposite limit, when there is no solid matrix strain $\left(\mathbf{f}_{n}^{e}=\mathbf{0}\right)$ and the interstitial fluid pressure supports the entire contact load, $\mathbf{f}_{n}^{p}=\mathbf{f}_{n}$, the friction coefficient achieves its minimum value, $\mu_{e f f}=\varphi \mu_{e q}=\mu_{\text {min }}$.

Thus, unlike the preceding formulation, this model for load sharing accounts explicitly for the porosity of the contacting surfaces via the solid-to-solid contact area fraction $\varphi$. Even when

\footnotetext{
${ }^{1}$ The volume fraction is also equal to the area fraction according to Delesse's law (Mathieu-Costello, O., 1987. Stereology. In: Handbook of bioengineering. R. Skalak, and S. Chien, (Eds.). McGraw-Hill, New York, pp. 35.31-35.31.).
} 
$\mathbf{f}_{n}^{e}=\mathbf{0}$, the friction coefficient does not reduce to zero, but the minimum value it can achieve becomes smaller with decreasing $\varphi$ (Ateshian et al., 1998).

The forces normal to the interface are collinear and may be written in the form $\mathbf{f}_{n}^{\alpha}=W^{\alpha} \mathbf{n}$. Therefore, the expression for $\mu_{\text {eff }}$ in Eq.(8) may be simplified to

$$
\mu_{\mathrm{eff}}=\mu_{e q}\left[1-(1-\varphi) \frac{W^{p}}{W}\right]
$$

where $W^{p} / W$ represents the interstitial fluid load support. No absolute values are needed in this expression for $\mu_{\text {eff }}$, because the total contact load is always negative in compression, $W \leq 0$. When the interstitial fluid pressure is positive (above ambient conditions), $W^{p}$ is negative by the same argument, so that the interstitial fluid load support is a positive quantity ranging from $0 \%$ to $100 \%$. When the fluid pressure is negative (below ambient conditions, producing suction at the contact interface), then $W^{p}>0$ and the interstitial fluid load support becomes negative.

\section{Direct Validation of Friction Model}

A theoretical model may be tested against experiments in an effort to validate it. To explore the validity of the friction model embodied in Eq.(9), the most direct evidence can be achieved by measuring the frictional response and interstitial fluid pressurization in cartilage simultaneously.

Using the interstitial fluid pressure measurement technique refined in earlier studies (Park et al., 2003; Soltz and Ateshian, 1998; Soltz and Ateshian, 2000a; Soltz and Ateshian, 2000b), Krishnan et al. (Krishnan et al., 2004b) performed such measurements by testing the frictional response of cylindrical bovine cartilage plugs against glass, under unconfined compression creep. Consistent with previous studies, these investigators observed that the friction coefficient of cartilage rises over time, from an average of $\mu_{\min }=0.010$ to $\mu_{\text {eff }}=0.24$ over a median time of 75 minutes. Furthermore, they observed that the interstitial fluid load support, $W^{p} / W$, simultaneously decreased from $89 \%$ to $9 \%$. According to the model of Eq.(9), the friction coefficient should be a linear function of $W^{p} / W$ as both variables vary over time. This linear relation was confirmed from those experiments (Fig. 3), providing the first direct evidence of agreement between a theoretical model and experimental measurements of cartilage friction. A least-squares fit of this linear response yielded average values of $\mu_{e q}=$ 0.28 and $\varphi=2 \%$.

These results demonstrated that the friction coefficient of cartilage is very low when the interstitial fluid load support is highest, yielding values of $\mu_{\min }$ that rival or improve over the best artificial bearing types ever designed (Ateshian and Mow, 2005). However, as $W^{p} / W$ reduces to zero, $\mu_{e q}$ rises to a relatively elevated value that reflects poor tribological performance. An obvious question arising from these observations is whether in situ conditions prevailing in diarthrodial joints would allow the friction coefficient to rise as much.

Since physiological loading conditions generally involve cyclical and intermittent loads, it was hypothesized that dynamic compressive loading of a disk of cartilage may sustain dynamic interstitial fluid pressurization indefinitely, always keeping the friction coefficient low (Krishnan et al., 2005). This hypothesis was tested experimentally and, contrary to expectation, the friction coefficient of cartilage against glass under dynamic loading was observed to rise at the same rate as under static loading, while fluctuating above and below the static loading value (Fig. 4a). For example, under cyclical loading at $0.5 \mathrm{~Hz}$, static loading produced an equilibrium friction coefficient of $\mu_{e q}=0.15$, while dynamic loading achieved a steady-state cycle where $\mu_{\text {eff }}$ fluctuated from 0.08 to 0.36 (Krishnan et al., 2005). 
This intriguing outcome was examined using the theoretical model of Eq.(9), coupled with a biphasic analysis of unconfined compression to predict the interstitial fluid load support (Krishnan et al., 2005). Theory demonstrated that sustained dynamic loading does not keep the interstitial fluid pressure elevated; over time, the mean value of the pressure returns to zero, just as in static loading, while each loading cycle produces positive and negative fluctuations about this mean response. This fluctuation between positive and negative values accompanies the cyclical inflow and outflow of interstitial fluid from the lateral surface of the disk, producing zero net flow under steady-state conditions. The resulting intermittently negative interstitial fluid load support, which produces suction at the cartilage-glass interface, was able to explain how the friction coefficient could be intermittently higher than that achieved under static loading (Fig. 4b).

Thus, while the hypothesis of this study was rejected, the agreement between the unusual experimental findings and the predictions of the theoretical model reinforced the evidence in support of the theory. No prior study had focused on the frictional response of cartilage under cyclical compression, nor reported such large fluctuations in the friction coefficient. Yet, the friction model of Eq.(9) provided a straightforward explanation for this observation. Other prevailing theories for lubrication in cartilage (fluid-film lubrication or boundary lubrication) are unable to explain this response.

Since dynamic loading could not explain how the friction coefficient may remain low under physiological conditions in situ, alternative explanations had to be explored. The biphasic theory has shown that the temporal response of the solid matrix deformation and interstitial fluid pressure of cartilage is characterized by a time constant $\tau$ which is proportional to $a^{2} /$ $H_{A} k$, where $a$ is a characteristic dimension of the tissue along the predominant direction of interstitial fluid flow, $H_{A}$ is a characteristic measure of the solid matrix modulus, and $k$ is a measure of the tissue's permeability to interstitial fluid (Armstrong et al., 1984; Mak et al., 1987; Mow et al., 1980). For example, in the case of a cartilage disk subjected to unconfined compression, $a$ is its radius.

Combining this understanding with the friction model of Eq.(9), it was hypothesized that the time constant for the rise of $\mu_{\text {eff }}$ in the frictional response of cartilage disks against glass should increase quadratically with the disk radius (thus linearly with the cross-sectional area) (Carter et al., 2007). Experiments performed on 4, 6 and $8 \mathrm{~mm}$ diameter disks confirmed this hypothesis (Fig. 5), providing further evidence in support of interstitial fluid pressurization as a dominant mechanism regulating the frictional response of cartilage. For example, in the case of the largest disk size, the time constant for the rise of $\mu_{\text {eff }}$ averaged 70 minutes under a contact pressure of $0.25 \mathrm{MPa}$; extrapolating those results to contact areas and stresses representative of lower extremity diarthrodial joints, it is reasonable to expect that this time constant in vivo is on the order of several hours.

While these results were encouraging, the concern remained that activities of daily living typically span 16 hours, implying that the friction coefficient could indeed rise to detrimental levels as the day progresses. Could there be another characteristic of physiological loading conditions overlooked in these experiments, which might keep the friction coefficient low? Here again, the benefit of having a theoretical model facilitates the formulation of testable hypotheses. In an earlier theoretical study of articular contact between biphasic cylindrical layers of cartilage (Ateshian and Wang, 1995), it was shown that rolling or sliding contact can sustain elevated interstitial fluid pressurization indefinitely, under steady-state conditions, as long as the rolling or sliding velocity $V$ is substantially greater than the characteristic velocity $H_{A} k / a$ of interstitial fluid flow in the tissue. The ratio of the convective velocity of sliding and the diffusive velocity of interstitial fluid flow represents the Peclet number for this problem, $P_{e}=V a / H_{A} k$, where $a$ represents a characteristic measure of the interstitial fluid flow path 
length, such as the contact area semi-width. Thus, this earlier theoretical study demonstrated that the interstitial fluid load support $W^{p} / W$ approaches unity when $P_{e} \gg 1$; conversely, when $P_{e} \ll 1, W^{p} / W$ approaches zero. Subsequent finite element modeling confirmed this earlier report (Pawaskar et al., 2007).

The physical interpretation for this finding is that a contact region that migrates over an articular surface induces interstitial fluid pressurization; if the migration speed is higher than the diffusive interstitial fluid velocity, the pressurized fluid has little time to escape to low pressure regions before the contact traction moves on. Conversely, if the contact region migrates much more slowly than the interstitial fluid can flow through the tissue, there is ample time for the pressurized fluid to flow away from the loaded region, and the interstitial fluid pressure subsides under steady-state rolling or sliding conditions.

That this mechanism of migrating contact could be responsible for maintaining low friction in cartilage over sustained periods of time was suggested first from theory (Ateshian, 1997).

Interestingly, the first experimental evidence in support of this mechanism was observed in the case when $P_{e} \ll 1$, when measuring the friction coefficient of articular cartilage using atomic force microscopy (AFM) with a small spherical polystyrene probe (Park et al., 2004). For articular cartilage, the orders of magnitude for its material properties are $H_{A} \sim 1 \mathrm{MPa}$ and $k \sim 10^{-3} \mathrm{~mm}^{4} / \mathrm{N} \cdot \mathrm{s}$; if an AFM probe has a radius $a \sim 10^{-3} \mathrm{~mm}$ and rasterizes the articular surface at a typical velocity $V \sim 0.1 \mathrm{~mm} / \mathrm{s}$, then $P_{e} \sim 0.1$, suggesting that the interstitial fluid load support is negligible in AFM friction measurements. Indeed, consistent with this theoretical prediction, the friction coefficient observed in such measurements have been found to be comparable to values of $\mu_{e q}$ as reported from macroscopic tests, with values in the range 0.15-0.25 (Coles et al., 2008; Park et al., 2004).

In the case of macroscopic testing of cartilage friction under migrating contact areas, strong evidence in support of this sustained interstitial fluid pressurization mechanism was observed with the finding that the friction coefficient remained nearly constant, at $\sim 0.03$, over one hour of testing, when sliding a cartilage plug against a larger cartilage surface (Bell et al., 2006). In this case, when $V \sim 1 \mathrm{~mm} / \mathrm{s}$ and $a \sim 1 \mathrm{~mm}$, it may be estimated that $P_{e^{\sim}} 10^{3}$, implying that the interstitial fluid load support may be sustained at elevated values for an indefinite period of time. Indeed, this migrating contact mechanism was further confirmed in a subsequent friction study of cartilage condyle against cartilage tibial plateau, and glass lens against tibial plateau (Fig. 6), which explicitly explored the relation between the friction coefficient and the Peclet number (Caligaris and Ateshian, 2008a). This study reported an experimental variation of the friction coefficient over four decades of the Peclet number $\left(1 \leq P_{e} \leq 1000\right.$, Fig. 7) consistent with predictions of the interstitial fluid load support from theory (Ateshian and Wang, 1995) and the associated friction model of Eq.(9). Thus, when the sliding velocity was on the order of physiological values $\left(0.5\right.$ to $\left.5 \mathrm{~mm} / \mathrm{s}, P_{e} \gg 1\right)$, the friction coefficient was $\sim 0.025$; as the sliding velocity dropped to $0.005 \mathrm{~mm} / \mathrm{s}\left(P_{e^{\sim 1}}\right), \mu_{\text {eff }}$ increased to $\sim 0.16$.

An important aspect of the concept of migrating contact areas between two articular surfaces is that it matters not whether the contact area remains mostly stationary on one of the surfaces, as long as it migrates on the other. For example, in the glenohumeral joint of the shoulder, the contact area on the glenoid is mostly stationary, while it migrates on the humeral head during various activities such as abduction-adduction and flexion-extension. Indeed, in the context of the biphasic theory, the interstitial fluid pressure is continuous across a contact interface (Ateshian et al., 1994; Hou et al., 1989). Thus, if fluid pressurization is promoted by a contact area migrating on one articular layer, the resulting elevated pressure will also prevail in the opposing articular layer. 
All diarthrodial joints undergo rolling or sliding contact during normal activities of daily living, as demonstrated in experimental studies of articular contact during normal activities of daily living, such as the tibiofemoral (Ahmed and Burke, 1983; Walker and Hajek, 1972), patellofemoral (Ahmed et al., 1983; Huberti and Hayes, 1984), glenohumeral (Soslowsky et al., 1992), trapeziometacarpal (Ateshian et al., 1995), tibiotalar (Kura et al., 1998; Millington et al., 2007), and hip joints (von Eisenhart et al., 1999). Therefore, the concept that migrating contact can promote sustained interstitial fluid pressurization and reduce the friction coefficient is not limited to lower extremity joints. Coupled with the recognition that congruent contact (relatively larger contact areas) lengthens the time constant for loss of fluid pressurization under constant loading (Caligaris and Ateshian, 2008a; Carter et al., 2007), the hypothesis that there is negligible loss of pressurization and concomitant rise in friction during activities of daily living becomes increasingly convincing.

\section{Effects of Tissue Degradation}

Since the frictional response of cartilage is so clearly dependent on the interstitial fluid load support, it would appear sensible to hypothesize that degradative mechanisms associated with cartilage and joint degenerative diseases, which are known to affect the modulus and permeability of cartilage (Setton et al., 1999), may also alter its frictional response. Interestingly, the literature on this subject has shown mixed results.

Following cartilage digestion with chondroitinase AC, Pickard et al. (Pickard et al., 1998) reported no change in the friction coefficient of cartilage against a smooth cobalt-chrome counterface, over its entire temporal response, even though the digested cartilage deformed at a faster rate than the control tissue. In these studies, $\mu_{\text {eff }}$ was observed to rise to an equilibrium value of $\mu_{e q} \sim 0.35$. In another investigation of the frictional response following chondroitinase $\mathrm{ABC}$ digestion, Kumar et al. (Kumar et al., 2001) reported an increase in the friction coefficient in the early time response (akin to the value of $\mu_{\mathrm{min}}$ ), from 0.0028 to 0.0043 when tested in saline.

Basalo et al. (Basalo et al., 2004) demonstrated that degradation of immature bovine cartilage by chondroitinase $\mathrm{ABC}$ or collagenase can lead to a significant reduction in the peak interstitial fluid load support $W^{p} / W$, from $\sim 80 \%$ down to $\sim 50 \%$. They followed up these investigations by testing the frictional response of cartilage against glass, under the loading configuration of stress-relaxation, before and after chondroitinase $\mathrm{ABC}$ digestion, and found that both $\mu_{\min }$ and $\mu_{e q}$ increased significantly ( $\mu_{\min }$ from 0.047 to 0.082 , and $\mu_{e q}$ from 0.18 to 0.23 ). According to the friction model of Eq.(9), alterations in the interstitial fluid load support $W^{p} / W$ following enzymatic digestion only influence the ratio $\mu_{e f f} / \mu_{e q}$; in particular, a reduction in the peak interstitial fluid load support increases $\mu_{\min } / \mu_{e q}=1-(1-\varphi)\left(W^{p} / W\right)^{\max }$. (Any changes to $\mu_{e q}$ cannot result from alterations in $W^{p} / W$, and thus must be attributed to direct effects of the enzymatic digestion, a topic addressed in the next section.) The statistical increase observed in $\mu_{\min } / \mu_{e q}$ in this study (Basalo et al., 2004) supported the expectation that tissue degradation can alter the frictional response of cartilage via pathways affecting the interstitial fluid load support (Fig. 8). In a follow-up chondroitinase ABC digestion study however, when using the loading configuration of creep, no statistical change was observed in the ratio $\mu_{m i n} / \mu_{e q}$, even though $\mu_{e q}$, was still observed to increase (Basalo et al., 2006).

In contrast, when tissue degradation was induced by mechanical abrasion (Bell et al., 2006; Northwood and Fisher, 2007; Tanaka et al., 2005), the friction coefficient has been consistently observed to increase; these alterations could be attributed to a concomitant increase in $\mu_{e q}$, though some of these studies also show that the friction coefficient rises more rapidly over time (Bell et al., 2006), implying alterations in the interstitial fluid load support. 
Interestingly, few studies have investigated the frictional response of osteoarthritic cartilage, as most of the prior literature employed enzymatic or mechanical techniques to degrade normal tissue. In a recent study (Caligaris and Ateshian, 2008b) examining the frictional response of human patellofemoral joints with various degrees of osteoarthritis, under the configuration of migrating contact, no significant effect of tissue degradation was observed on the friction coefficient. This study did not include joints with end stage disease, where the subchondral bone might be exposed.

To summarize these findings, tissue degradation does not necessarily lead to an increase in the friction coefficient. In the single study where the interstitial fluid load support was reported (Basalo et al., 2005), the observed increase in the minimum friction coefficient was consistent with the decrease in peak interstitial fluid load support. In the remaining studies reviewed above, no direct measurement or estimation of the interstitial fluid pressurization was attempted. Consequently, it remains unclear whether various forms of tissue degradation necessarily produce a decrease in peak interstitial fluid pressurization. Indeed, according to the biphasic theory, the time constant $\tau$ for the temporal response of the fluid pressure, which is proportional to $a^{2} / H_{A} k$, may not change substantially if the tissue degradation leads to a decrease in $H_{A}$ (softening) and an increase in $k$ (greater permeability) such that the product $H_{A} k$ remains essentially unaltered. The same argument applied to the Peclet number $P_{e}=\mathrm{Val}$ $H_{A} k$.

These experimental results and theoretical predictions suggest that the main tribological function of articular cartilage may be more resilient to advancing tissue degeneration than might otherwise be assumed. This interesting outcome may explain one thread in the complex fabric of joint degenerative disease, where radiographic evidence of tissue degeneration is not always associated with symptomatic osteoarthritis.

\section{Facilitating the Investigation of Boundary Lubrication}

Understanding the role of interstitial fluid pressurization on the frictional response of articular cartilage considerably facilitates the investigation of boundary lubrication mechanisms imparted by molecular constituents of synovial fluid (Hills, 1989; Jay, 1992; Schmidt et al., 2007; Swann et al., 1984) and the superficial zone of articular cartilage (Basalo et al., 2007; Basalo et al., 2006; Flannery et al., 1999; Jay et al., 2001; Krishnan et al., 2004a). Indeed, to ascertain the role of boundary lubricants on the cartilage friction coefficient, without the confounding effects of temporal variations in interstitial fluid pressurization, a testing configuration can be used which allows the fluid pressure to subside. As shown in Eq.(9), when $W^{P} / W=0$, the friction coefficient reduces to its equilibrium value $\mu_{e q}$. Thus, any alterations in $\mu_{e q}$ resulting from the addition or removal of molecular species at the articular surface can be attributed unambiguously to their boundary lubrication properties.

As reported above, testing configurations that allow the interstitial fluid pressurization to subside may be achieved by maintaining the contact area stationary on the articular surfaces, or letting $P_{e} \ll<1$ in the case of migrating contact areas. They include testing a cartilage cylindrical explant against an impermeable surface, such as metal (Forster and Fisher, 1996; Forster and Fisher, 1999) or glass (Caligaris and Ateshian, 2008a), or AFM testing with a polystyrene (Park et al., 2004) or colloidal (Coles et al., 2008) probe; it is also possible to configure testing of cartilage against cartilage while keeping the contact area stationary, using rotational sliding (Schmidt and Sah, 2007).

Based on such measurements, it has been established unequivocally that synovial fluid contains boundary lubricants since it is able to reduce the value of $\mu_{e q}$ significantly, when compared to a saline control (Caligaris and Ateshian, 2008a; Forster and Fisher, 1996; Forster and Fisher, 1999; Schmidt and Sah, 2007). These studies suggest that, on average, $\mu_{e q}$ may be reduced by 
a factor of $\sim 2$ when using synovial fluid instead of saline; for example, in the study of Schmidt and Sah (Schmidt and Sah, 2007) the friction coefficient reduced from 0.43 to 0.19 , and in the study of Caligaris et al. (Caligaris and Ateshian, 2008a) it reduced from 0.16 to 0.09 . The exact nature of the boundary lubricants found in synovial fluid or the superficial zone of cartilage is an active topic of investigation that merits its own separate review (Ateshian and Mow, 2005; Sah, 2009), and is not covered here.

According to Eq.(9), alterations in $\mu_{e q}$ affect the entire temporal response of the friction coefficient $\mu_{\text {eff }}$. Therefore it may be tempting to conclude that waiting for interstitial fluid pressurization to subside is not necessary when investigating boundary lubrication. However, by that argument, the comparison of $\mu_{\text {eff }}$ between the control group and alternative treatments should be performed at precisely the same value of $W^{p} / W$; in practice, unless $W^{p} / W$ is measured directly or estimated accurately, this is not possible to achieve except under equilibrium conditions when $W^{P} / W \rightarrow 0$. This is particularly true when the treatment affects the mechanical properties of cartilage (such as $H_{A}$ and $k$ ) in a manner that alters the temporal response of the interstitial fluid load support in a stationary contact area experiment, or the Peclet number in a migrating contact area experiment. In that case, there is no objective basis to compare the values of $\mu_{\text {eff }}$ between various groups and expect to extract information exclusive to boundary lubrication mechanisms.

\section{Conclusion}

For many decades the literature on cartilage biotribology was unable to conclusively identify the modes of lubrication prevailing in articular cartilage. For some investigators, the attractiveness of fluid-film lubrication was difficult to overcome, particularly in light of the fact that alternative theories such as weeping, boosted and boundary lubrication, did not appear to provide stronger experimental support. However, with advances in theoretical modeling of the porous-permeable nature of articular cartilage, it became possible to test alternative lubrication theories by comparing their predictions against experimental data. Over the course of the 1990s, it became apparent from theory that the porous nature of this tissue is not well suited for fluid-film lubrication, because the pores provide a pathway for the depletion of the pressurized lubricant film. Experimental measurements on cartilage explants confirmed this prediction by demonstrating that the friction response did not follow standard predictions from fluid film theory.

By formulating an alternative friction model that hypothesized a dependence of the friction coefficient on interstitial fluid load support, specific predictions were advanced with regard to the interstitial fluid load support and frictional response under static and dynamic loading, and under stationary versus migrating contact area. Each of these predictions was supported by experimental data that demonstrated a response consistent with the theoretical framework. These experimental studies were significantly enhanced by technological developments such as micro-electromechanical pressure sensors for measuring cartilage interstitial fluid pressure, and atomic force microscopy for measuring the friction coefficient on a micro-scale.

These studies have conclusively demonstrated that interstitial fluid load support plays a dominant role in regulating the frictional response of cartilage. With the availability of an experimentally validated theoretical framework, it is now understood that the friction coefficient of cartilage remains low as long as the interstitial fluid load support is elevated. This mechanism can be explained by the fact that the pressurized interstitial fluid supports most of the normal load transmitted across the articular surfaces, thereby minimizing the frictional force between the contacting porous solid matrices since they support only a small fraction of the normal load. The concept that a pressurized fluid can support most or all the load transmitted across bearing surfaces is consistent with hydrostatic lubrication. In cartilage, 
this interstitial pressurization arises from the applied compression. It can be sustained indefinitely as long as the contact area migrates over at least one of the contacting articular surfaces; under stationary contact, the time until the fluid pressurization subsides depends on the size of the contact area, and thus the congruence of the contact.

Once the role of interstitial fluid pressurization was clarified, the investigation of boundary lubricants present in synovial fluid and the superficial zone of articular cartilage became more straightforward. To avoid the confounding effects of the temporal response of fluid pressurization, it suffices to perform experiments that allow this pressurization to subside in order to isolate the effectiveness of boundary lubricants. This area of investigation is currently very active, as the role of boundary lubricants is believed to extend beyond the simple reduction of the friction coefficient, potentially also providing protection against wear (Jay et al., 2007).

The progress of cartilage lubrication research serves as an excellent illustration of the combination of theoretical and experimental advances in biomechanics. Experimental findings initially motivated the formulation of various conventional and novel hypotheses on the prevailing modes of lubrication. For many decades however, a conclusive consensus could not emerge because existing theories could not predict experimental results consistently. As theoretical modeling of cartilage progressed, new tools became available to address and refine existing hypotheses, eventually leading to a remarkable agreement with experiments, thereby providing a clearer understanding of this fundamental function of articular cartilage.

\section{Acknowledgments}

The author's studies related to cartilage mechanics and lubrication were supported by the National Institute of Arthritis, Musculoskeletal and Skin Diseases of the U.S. National Institutes of Health (AR43628). The author would like to acknowledge the contributions to these studies of former and current students, Dr. Huiqun (Laura) Wang, Dr. Michael A. Soltz, Dr. Ramaswamy Krishnan, Dr. Monika Kopacz, Dr. Seonghun Park, Dr. Ines M. Basalo, Dr. Nadeen O. Chahine, Mr. Michael Carter, Mr. Matteo Caligaris, Mr. Michael Kaplun, and Mr. Liming Bian, as well as faculty colleagues, Dr. Kevin D. Costa, Dr. Hui Chen, Dr. Christopher Ahmad, and Dr. Clark T. Hung.

\section{References}

Ahmed AM, Burke DL. In-vitro measurement of static pressure distribution in synovial joints--Part I: Tibial surface of the knee. J Biomech Eng 1983;105:216-225. [PubMed: 6688842]

Ahmed AM, Burke DL, Yu A. In-vitro measurement of static pressure distribution in synovial joints-Part II: Retropatellar surface. J Biomech Eng 1983;105:226-236. [PubMed: 6632824]

Almeida ES, Spilker RL. Mixed and Penalty Finite Element Models for the Nonlinear Behavior of Biphasic Soft Tissues in Finite Deformation: Part I - Alternate Formulations. Comput Methods Biomech Biomed Engin 1997;1:25-46. [PubMed: 11264795]

Armstrong CG, Lai WM, Mow VC. An analysis of the unconfined compression of articular cartilage. J Biomech Eng 1984;106:165-173. [PubMed: 6738022]

Ateshian GA. A theoretical formulation for boundary friction in articular cartilage. J Biomech Eng 1997;119:81-86. [PubMed: 9083853]

Ateshian GA, Ark JW, Rosenwasser MP, Pawluk RJ, Soslowsky LJ, Mow VC. Contact areas in the thumb carpometacarpal joint. J Orthop Res 1995;13:450-458. [PubMed: 7602407]

Ateshian GA, Lai WM, Zhu WB, Mow VC. An asymptotic solution for the contact of two biphasic cartilage layers. J Biomech 1994;27:1347-1360. [PubMed: 7798285]

Ateshian, GA.; Mow, VC. Lubrication and wear of diarthrodial joints. In: Mow, VC.; Huiskes, R., editors. Basic orthopaedic biomechanics \& mechano-biology. Philadelphia, Pa.; London: Lippincott Williams \& Wilkins; 2005.

Ateshian GA, Wang H. A theoretical solution for the frictionless rolling contact of cylindrical biphasic articular cartilage layers. J Biomech 1995;28:1341-1355. [PubMed: 8522547] 
Ateshian GA, Wang H, Lai WM. The role of interstitial fluid pressurization and surface porosities on the boundary friction of articular cartilage. J Tribol 1998;120:241-248.

Basalo IM, Chahine NO, Kaplun M, Chen FH, Hung CT, Ateshian GA. Chondroitin sulfate reduces the friction coefficient of articular cartilage. J Biomech 2007;40:1847-1854. [PubMed: 17084404]

Basalo IM, Chen FH, Hung CT, Ateshian GA. Frictional response of bovine articular cartilage under creep loading following proteoglycan digestion with chondroitinase ABC. J Biomech Eng 2006;128:131-134. [PubMed: 16532626]

Basalo IM, Mauck RL, Kelly TA, Nicoll SB, Chen FH, Hung CT, Ateshian GA. Cartilage interstitial fluid load support in unconfined compression following enzymatic digestion. J Biomech Eng 2004;126:779-786. [PubMed: 15796336]

Basalo IM, Raj D, Krishnan R, Chen FH, Hung CT, Ateshian GA. Effects of enzymatic degradation on the frictional response of articular cartilage in stress relaxation. J Biomech 2005;38:1343-1349. [PubMed: 15863119]

Bell CJ, Ingham E, Fisher J. Influence of hyaluronic acid on the time-dependent friction response of articular cartilage under different conditions. Proc Inst Mech Eng [H] 2006;220:23-31.

Bi X, Li G, Doty SB, Camacho NP. A novel method for determination of collagen orientation in cartilage by Fourier transform infrared imaging spectroscopy (FT-IRIS). Osteoarthritis Cartilage 2005;13:1050-1058. [PubMed: 16154778]

Bowen, RM. Theory of mixtures. New York: Academic Press; 1976.

Bowen RM. Incompressible porous media models by use of the theory of mixtures. International Journal of Engineering Science 1980;18:1129-1148.

Caligaris M, Ateshian GA. Effects of sustained interstitial fluid pressurization under migrating contact area, and boundary lubrication by synovial fluid, on cartilage friction. Osteoarthritis Cartilage 2008a; 16:1220-1227. [PubMed: 18395475]

Caligaris, M.; Ateshian, GA. Transactions of the Orthopaedic Research Society. San Francisco, CA: 2008b. Investigation of the frictional response of osteoarthritic human tibiofemoral joints and the potential beneficial tribological effect of healthy synovial fluid; p. 0211

Carter MJ, Basalo IM, Ateshian GA. The temporal response of the friction coefficient of articular cartilage depends on the contact area. J Biomech 2007;40:3257-3260. [PubMed: 17490673]

Chahine NO, Wang CC, Hung CT, Ateshian GA. Anisotropic strain-dependent material properties of bovine articular cartilage in the transitional range from tension to compression. J Biomech 2004;37:1251-1261. [PubMed: 15212931]

Charnley J. The lubrication of animal joints in relation to surgical reconstruction by arthroplasty. Ann Rheum Dis 1960;19:10-19. [PubMed: 13809345]

Cohen B, Lai WM, Mow VC. A transversely isotropic biphasic model for unconfined compression of growth plate and chondroepiphysis. J Biomech Eng 1998;120:491-496. [PubMed: 10412420]

Coles JM, Blum JJ, Jay GD, Darling EM, Guilak F, Zauscher S. In situ friction measurement on murine cartilage by atomic force microscopy. J Biomech 2008;41:541-548. [PubMed: 18054362]

Dowson D. Lubrication and wear of joints. Physiotherapy 1973;59:104-106. [PubMed: 4790905]

Dowson D, Wright V, Longfield MD. Human joint lubrication. Biomed Eng 1969;4:160-165. [PubMed: 5793726]

Flannery CR, Hughes CE, Schumacher BL, Tudor D, Aydelotte MB, Kuettner KE, Caterson B. Articular cartilage superficial zone protein (SZP) is homologous to megakaryocyte stimulating factor precursor and Is a multifunctional proteoglycan with potential growth-promoting, cytoprotective, and lubricating properties in cartilage metabolism. Biochem Biophys Res Commun 1999;254:535-541. [PubMed: 9920774]

Forster H, Fisher J. The influence of loading time and lubricant on the friction of articular cartilage. Proc Inst Mech Eng [H] 1996;210:109-119.

Forster H, Fisher J. The influence of continuous sliding and subsequent surface wear on the friction of articular cartilage. Proc Inst Mech Eng [H] 1999;213:329-345.

Frank EH, Grodzinsky AJ, Koob TJ, Eyre DR. Streaming potentials: a sensitive index of enzymatic degradation in articular cartilage. J Orthop Res 1987;5:497-508. [PubMed: 3681524] 
Frank, EH.; Grodzinsky, AJ.; Phillips, SL.; Grimshaw, PE. Physicochemical and bioelectrical determinants of cartilage material properties. In: Mow, VC.; Ratcliffe, A.; Woo, SL., editors. Biomechanics of diarthrodial joints. New York: Springer-Verlag; 1990. p. 261-282.

Gleghorn JP, Bonassar LJ. Lubrication mode analysis of articular cartilage using Stribeck surfaces. J Biomech. 2008

Hamrock, BJ. Fundamentals of fluid film lubrication. New York: McGraw-Hill; 1994.

Hayes WC, Bodine AJ. Flow-independent viscoelastic properties of articular cartilage matrix. J Biomech 1978;11:407-419. [PubMed: 213441]

Hills BA. Oligolamellar lubrication of joints by surface active phospholipid. J Rheumatol 1989;16:8291. [PubMed: 2716011]

Hlavacek M. The role of synovial fluid filtration by cartilage in lubrication of synovial joints--I. Mixture model of synovial fluid. J Biomech 1993a;26:1145-1150. [PubMed: 8253819]

Hlavacek M. The role of synovial fluid filtration by cartilage in lubrication of synovial joints--II. Squeezefilm lubrication: homogeneous filtration. J Biomech 1993b;26:1151-1160. [PubMed: 8253820]

Hlavacek M. The role of synovial fluid filtration by cartilage in lubrication of synovial joints--IV. Squeeze-film lubrication: the central film thickness for normal and inflammatory synovial fluids for axial symmetry under high loading conditions. J Biomech 1995;28:1199-1205. [PubMed: 8550638]

Hlavacek M. Lubrication of the human ankle joint in walking with the synovial fluid filtrated by the cartilage with the surface zone worn out: steady pure sliding motion. J Biomech 1999;32:1059-1069. [PubMed: 10476844]

Hlavacek M. Squeeze-film lubrication of the human ankle joint with synovial fluid filtrated by articular cartilage with the superficial zone worn out. J Biomech 2000;33:1415-1422. [PubMed: 10940400]

Hlavacek M. The thixotropic effect of the synovial fluid in squeeze-film lubrication of the human hip joint. Biorheology 2001;38:319-334. [PubMed: 11673647]

Hlavacek M, Novak J. The role of synovial fluid filtration by cartilage in lubrication of synovial joints-III. Squeeze-film lubrication: axial symmetry under low loading conditions. J Biomech 1995;28:1193-1198. [PubMed: 8550637]

Hou JS, Holmes MH, Lai WM, Mow VC. Boundary conditions at the cartilage-synovial fluid interface for joint lubrication and theoretical verifications. J Biomech Eng 1989;111:78-87. [PubMed: 2747237]

Huberti HH, Hayes WC. Patellofemoral contact pressures. The influence of q-angle and tendofemoral contact. J Bone Joint Surg Am 1984;66:715-724. [PubMed: 6725318]

Jay GD. Characterization of a bovine synovial fluid lubricating factor. I. Chemical, surface activity and lubricating properties. Connect Tissue Res 1992;28:71-88. [PubMed: 1628491]

Jay GD, Tantravahi U, Britt DE, Barrach HJ, Cha CJ. Homology of lubricin and superficial zone protein (SZP): products of megakaryocyte stimulating factor (MSF) gene expression by human synovial fibroblasts and articular chondrocytes localized to chromosome 1q25. J Orthop Res 2001;19:677687. [PubMed: 11518279]

Jay GD, Torres JR, Rhee DK, Helminen HJ, Hytinnen MM, Cha CJ, Elsaid K, Kim KS, Cui Y, Warman ML. Association between friction and wear in diarthrodial joints lacking lubricin. Arthritis Rheum 2007;56:3662-3669. [PubMed: 17968947]

Jones ES. Joint lubrication. Lancet 1936;230:1043-1044.

Katta J, Jin Z, Ingham E, Fisher J. Biotribology of articular cartilage--a review of the recent advances. Med Eng Phys 2008;30:1349-1363. [PubMed: 18993107]

Kempson, GE. Mechanical properties of articular cartilage.. In: Freeman, MAR., editor. Adult Articular Cartilage. Kent: Pitman Medical; 1979. p. 333-414.

Krishnan R, Caligaris M, Mauck RL, Hung CT, Costa KD, Ateshian GA. Removal of the superficial zone of bovine articular cartilage does not increase its frictional coefficient. Osteoarthritis Cartilage 2004a; 12:947-955. [PubMed: 15564061]

Krishnan R, Kopacz M, Ateshian GA. Experimental verification of the role of interstitial fluid pressurization in cartilage lubrication. J Orthop Res 2004b;22:565-570. [PubMed: 15099636]

Krishnan R, Mariner EN, Ateshian GA. Effect of dynamic loading on the frictional response of bovine articular cartilage. J Biomech 2005;38:1665-1673. [PubMed: 15958224] 
Kumar P, Oka M, Toguchida J, Kobayashi M, Uchida E, Nakamura T, Tanaka K. Role of uppermost superficial surface layer of articular cartilage in the lubrication mechanism of joints. J Anat 2001;199:241-250. [PubMed: 11554503]

Kura H, Kitaoka HB, Luo ZP, An KN. Measurement of surface contact area of the ankle joint. Clin Biomech (Bristol, Avon) 1998;13:365-370.

Lai WM, Hou JS, Mow VC. A triphasic theory for the swelling and deformation behaviors of articular cartilage. J Biomech Eng 1991;113:245-258. [PubMed: 1921350]

Lai WM, Mow VC, Sun DD, Ateshian GA. On the electric potentials inside a charged soft hydrated biological tissue: streaming potential versus diffusion potential. J Biomech Eng 2000;122:336-346. [PubMed: 11036556]

Lewis PR, McCutchen CW. Experimental evidence for weeping lubrication in mammalian joints. Nature 1959;184:1285. [PubMed: 14416552]

Longfield MD, Dowson D, Walker PS, Wright V. "Boosted lubrication" of human joints by fluid enrichment and entrapment. Biomed Eng 1969;4:517-522. [PubMed: 5358942]

Macconaill MA. The Function of Intra-Articular Fibrocartilages, with Special Reference to the Knee and Inferior Radio-Ulnar Joints. J Anat 1932;66:210-227. [PubMed: 17104369]

Macirowski T, Tepic S, Mann RW. Cartilage stresses in the human hip joint. J Biomech Eng 1994;116:1018. [PubMed: 8189704]

Mak AF. The apparent viscoelastic behavior of articular cartilage--the contributions from the intrinsic matrix viscoelasticity and interstitial fluid flows. J Biomech Eng 1986;108:123-130. [PubMed: 3724099]

Mak AF, Lai WM, Mow VC. Biphasic indentation of articular cartilage--I. Theoretical analysis. J Biomech 1987;20:703-714. [PubMed: 3654668]

Malcom, LL. University of California; 1976. An experimental investigation of the frictional and deformational responses of articular cartilage interfaces to static and dynamic loading.

Maroudas A. Hyaluronic acid films. Proc Inst Mech Eng 1967;181:122-124.

Maroudas, A. Physicochemical properties of articular cartilage. In: Freeman, MAR., editor. Adult Articular Cartilage. Kent: Pitman Medical; 1979. p. 215-290.

Maroudas AI. Balance between swelling pressure and collagen tension in normal and degenerate cartilage. Nature 1976;260:808-809. [PubMed: 1264261]

Mathieu-Costello, O. Stereology In: Handbook of bioengineering. Skalak, R.; Chien, S., editors. New York: McGraw-Hill; 1987. pp. 35.31-35.31.

McCutchen CW. Sponge-hydrostatic and weeping bearings. Nature 1959;184:1284-1285.

McCutchen CW. The frictional properties of animal joints. Wear 1962;5:1-17.

McCutchen CW. Boundary lubrication by synovial fluid: demonstration and possible osmotic explanation. Fed. Proc 1966;25:1061. [PubMed: 5940985]

McCutchen CW. Joint lubrication. Bull Hosp Jt Dis Orthop Inst 1983;43:118-129. [PubMed: 6317095]

Millington S, Grabner M, Wozelka R, Hurwitz S, Crandall J. A stereophotographic study of ankle joint contact area. J Orthop Res 2007;25:1465-1473. [PubMed: 17580338]

Mow VC, Kuei SC, Lai WM, Armstrong CG. Biphasic creep and stress relaxation of articular cartilage in compression: Theory and experiments. J Biomech Eng 1980;102:73-84. [PubMed: 7382457]

Mow, VC.; Ratcliffe, A. Structure and function of articular cartilage and meniscus. In: Mow, VC.; Hayes, WC., editors. Basic orthopaedic biomechanics. Philadelphia: Lippincott-Raven; 1997. p. 514pp. xiii

Nieminen MT, Rieppo J, Toyras J, Hakumaki JM, Silvennoinen J, Hyttinen MM, Helminen HJ, Jurvelin JS. T2 relaxation reveals spatial collagen architecture in articular cartilage: a comparative quantitative MRI and polarized light microscopic study. Magn Reson Med 2001;46:487-493. [PubMed: 11550240]

Nissi MJ, Rieppo J, Toyras J, Laasanen MS, Kiviranta I, Jurvelin JS, Nieminen MT. T(2) relaxation time mapping reveals age- and species-related diversity of collagen network architecture in articular cartilage. Osteoarthritis Cartilage 2006;14:1265-1271. [PubMed: 16843689]

Northwood E, Fisher J. A multi-directional in vitro investigation into friction, damage and wear of innovative chondroplasty materials against articular cartilage. Clin Biomech (Bristol, Avon) 2007;22:834-842. 
Oloyede A, Broom N. Stress-sharing between the fluid and solid components of articular cartilage under varying rates of compression. Connect Tissue Res 1993;30:127-141. [PubMed: 8149745]

Oloyede A, Broom N. The biomechanics of cartilage load-carriage. Connect Tissue Res 1996;34:119143. [PubMed: 8909876]

Oloyede A, Broom ND. Is classical consolidation theory applicable to articular cartilage deformation? Clin Biomech (Bristol, Avon) 1991;6:206-212.

Overbeek JT. The Donnan equilibrium. Prog Biophys Biophys Chem 1956;6:57-84. [PubMed: 13420188]

Park S, Costa KD, Ateshian GA. Microscale frictional response of bovine articular cartilage from atomic force microscopy. J Biomech 2004;37:1679-1687. [PubMed: 15388310]

Park S, Krishnan R, Nicoll SB, Ateshian GA. Cartilage interstitial fluid load support in unconfined compression. J Biomech 2003;36:1785-1796. [PubMed: 14614932]

Pawaskar SS, Jin ZM, Fisher J. Modelling of fluid support inside articular cartilage during sliding. Proc Inst Mech Eng [J] 2007;221:165-174.

Pickard J, Ingham E, Egan J, Fisher J. Investigation into the effect of proteoglycan molecules on the tribological properties of cartilage joint tissues. Proc Inst Mech Eng [H] 1998;212:177-182.

Radin EL, Swann DA, Weisser PA. Separation of a hyaluronate-free lubricating fraction from synovial fluid. Nature 1970;228:377-378. [PubMed: 5473985]

Sah RL. Cartilage lubrication. Annu Rev Biomed Eng 2009:11.

Schmidt TA, Gastelum NS, Nguyen QT, Schumacher BL, Sah RL. Boundary lubrication of articular cartilage: role of synovial fluid constituents. Arthritis Rheum 2007;56:882-891. [PubMed: 17328061]

Schmidt TA, Sah RL. Effect of synovial fluid on boundary lubrication of articular cartilage. Osteoarthritis Cartilage 2007;15:35-47. [PubMed: 16859933]

Setton LA, Elliott DM, Mow VC. Altered mechanics of cartilage with osteoarthritis: human osteoarthritis and an experimental model of joint degeneration. Osteoarthritis Cartilage 1999;7:2-14. [PubMed: 10367011]

Soltz MA, Ateshian GA. Experimental verification and theoretical prediction of cartilage interstitial fluid pressurization at an impermeable contact interface in confined compression. J Biomech 1998;31:927934. [PubMed: 9840758]

Soltz MA, Ateshian GA. A Conewise Linear Elasticity mixture model for the analysis of tensioncompression nonlinearity in articular cartilage. J Biomech Eng 2000a;122:576-586. [PubMed: 11192377]

Soltz MA, Ateshian GA. Interstitial fluid pressurization during confined compression cyclical loading of articular cartilage. Ann Biomed Eng 2000b;28:150-159. [PubMed: 10710186]

Soltz MA, Basalo IM, Ateshian GA. Hydrostatic pressurization and depletion of trapped lubricant pool during creep contact of a rippled indenter against a biphasic articular cartilage layer. J Biomech Eng 2003;125:585-593. [PubMed: 14618917]

Soslowsky LJ, Flatow EL, Bigliani LU, Pawluk RJ, Ateshian GA, Mow VC. Quantitation of in situ contact areas at the glenohumeral joint: a biomechanical study. J Orthop Res 1992;10:524-534. [PubMed: 1613626]

Soulhat J, Buschmann MD, Shirazi-Adl A. A fibril-network-reinforced biphasic model of cartilage in unconfined compression. J Biomech Eng 1999;121:340-347. [PubMed: 10396701]

Spilker RL, de Almeida ES, Donzelli PS. Finite element methods for the biomechanics of soft hydrated tissues: nonlinear analysis and adaptive control of meshes. Crit Rev Biomed Eng 1992;20:279-313. [PubMed: 1478094]

Spilker RL, Suh JK. Formulation and evaluation of a finite element model for the biphasic model of hydrated soft tissues. Computers and Structures 1990;35:425-439.

Suh JK, Spilker RL, Holmes MH. A penalty finite element analysis for nonlinear mechanics of biphasic hydrated soft tissue under large deformation. International Journal for Numerical Methods in Engineering 1991;32:1411-1439.

Swann DA, Bloch KJ, Swindell D, Shore E. The lubricating activity of human synovial fluids. Arthritis Rheum 1984;27:552-556. [PubMed: 6721888] 
Swann DA, Radin EL. The molecular basis of articular lubrication. I. Purification and properties of a lubricating fraction from bovine synovial fluid. J Biol Chem 1972;247:8069-8073. [PubMed: 4629741]

Tanaka E, Iwabe T, Dalla-Bona DA, Kawai N, van Eijden T, Tanaka M, Kitagawa S, Takata T, Tanne $\mathrm{K}$. The effect of experimental cartilage damage and impairment and restoration of synovial lubrication on friction in the temporomandibular joint. J Orofac Pain 2005;19:331-336. [PubMed: 16279485]

Torzilli, PA.; Askari, E.; Jenkins, JT. Water content and solute diffusion properties in articular cartilage. In: Mow, VC.; Ratcliffe, A.; Woo, SL-Y., editors. Biomechanics of Diarthrodial Joints. New York: Springer-Verlag; 1990. p. 363-390.

Truesdell, C.; Toupin, R. Heidelberg: Springer; 1960. The classical field theories.

Unsworth A. Tribology of human and artificial joints. Proc Inst Mech Eng [H] 1991;205:163-172.

von Eisenhart R, Adam C, Steinlechner M, Muller-Gerbl M, Eckstein F. Quantitative determination of joint incongruity and pressure distribution during simulated gait and cartilage thickness in the human hip joint. J Orthop Res 1999;17:532-539. [PubMed: 10459759]

Walker PS, Dowson D, Longfield MD, Wright V. "Boosted lubrication" in synovial joints by fluid entrapment and enrichment. Ann Rheum Dis 1968;27:512-520. [PubMed: 5728097]

Walker PS, Dowson D, Longfield MD, Wright V. Lubrication of human joints. Ann Rheum Dis 1969;28:194. [PubMed: 5777249]

Walker PS, Hajek JV. The load-bearing area in the knee joint. J Biomech 1972;5:581-589. [PubMed: 4665894]

Walker PS, Unsworth A, Dowson D, Sikorski J, Wright V. Mode of aggregation of hyaluronic acid protein complex on the surface of articular cartilage. Ann Rheum Dis 1970;29:591-602. [PubMed: 5496062]

Wayne JS, Woo SL, Kwan MK. Application of the u-p finite element method to the study of articular cartilage. J Biomech Eng 1991;113:397-403. [PubMed: 1762436]

Wright V, Dowson D. Lubrication and cartilage. J Anat 1976;121:107-118. [PubMed: 3490]

Wu JZ, Herzog W, Epstein M. Evaluation of the finite element software ABAQUS for biomechanical modelling of biphasic tissues. J Biomech 1998;31:165-169. [PubMed: 9593211]

Xia Y, Ramakrishnan N, Bidthanapally A. The depth-dependent anisotropy of articular cartilage by Fourier-transform infrared imaging (FTIRI). Osteoarthritis Cartilage 2007;15:780-788. [PubMed: 17317225]

Xie T, Xia Y, Guo S, Hoover P, Chen Z, Peavy GM. Topographical variations in the polarization sensitivity of articular cartilage as determined by polarization-sensitive optical coherence tomography and polarized light microscopy. J Biomed Opt 2008;13054034

Zarek JM, Edward J. The stress-structure relationship in articular cartilage. Med Electron Biol Eng 1963;1:497-507. 

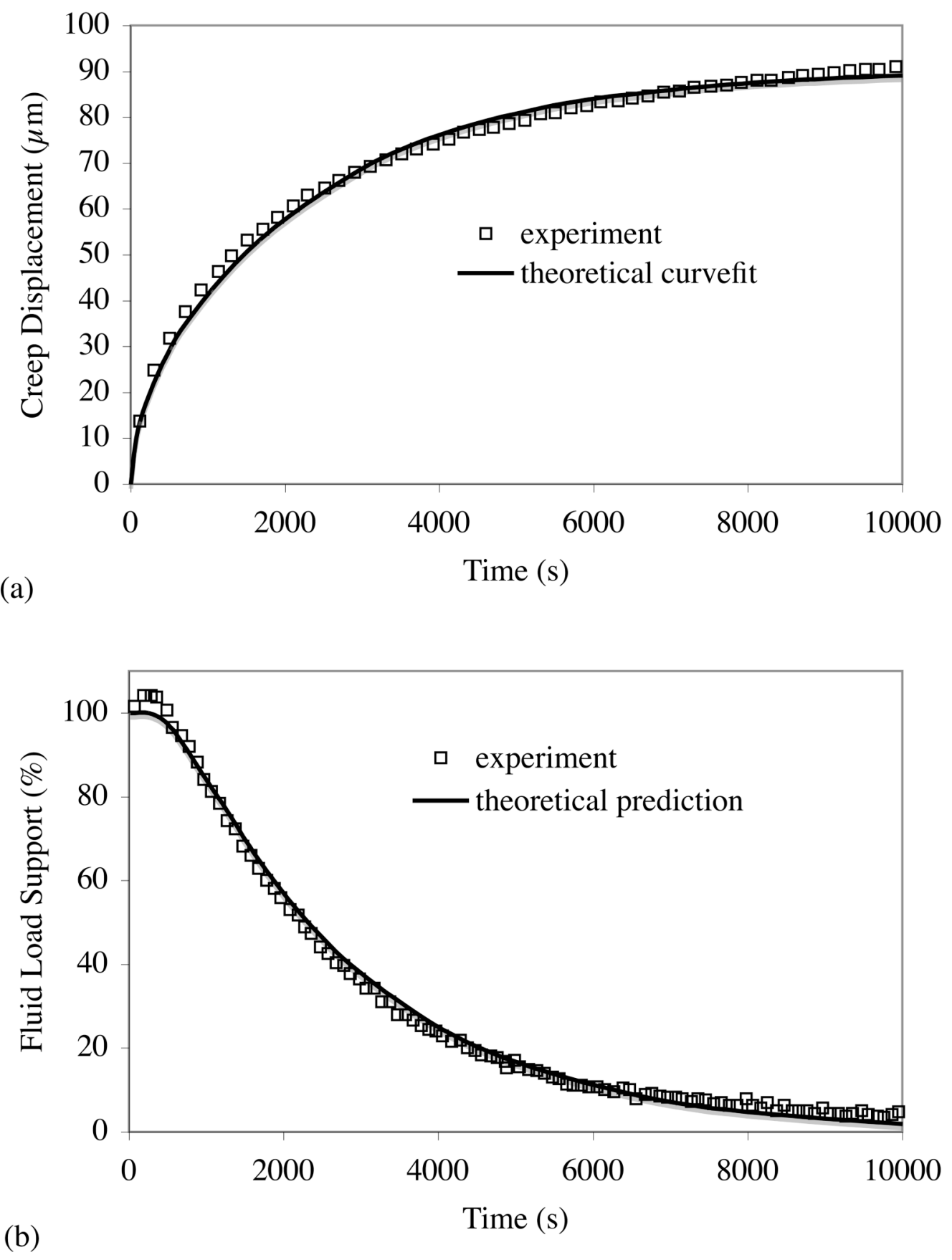

Fig. 1.

Confined compression creep response of bovine articular cartilage. (a) Creep deformation versus time; symbols denote experimental data and the solid curve represents a curve-fit of the experimental response using the biphasic theory. (b) Ratio of interstitial fluid pressure to applied stress, at the cartilage face abutting the bottom of the confining chamber; symbols denote experimental measurements and the solid curve represents the predicted response from the biphasic theory, using the material coefficients $H_{A}$ and $k$ obtained from curve-fitting the creep response. Reproduced from (Soltz and Ateshian, 1998) with permission. 


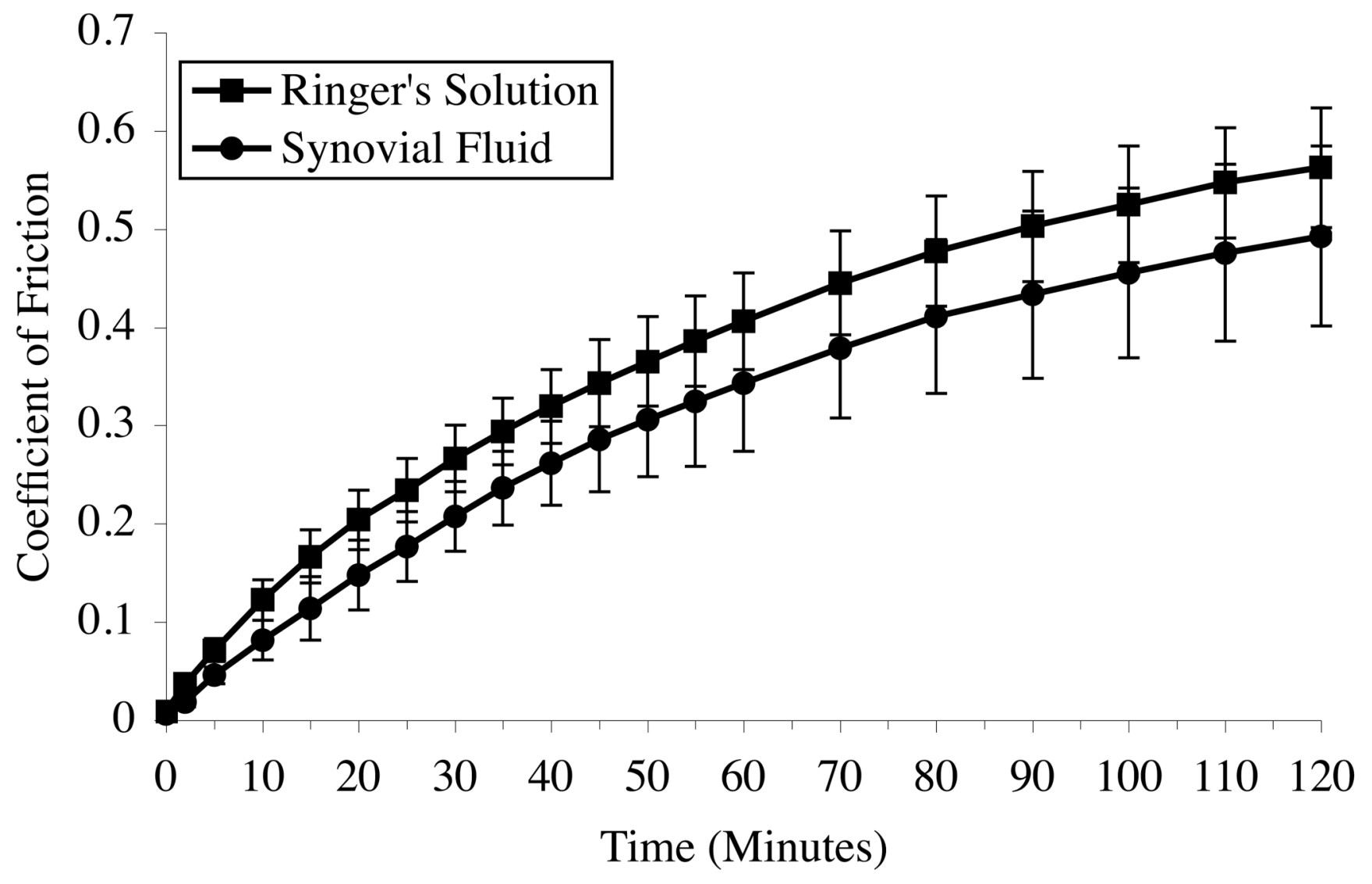

Fig. 2.

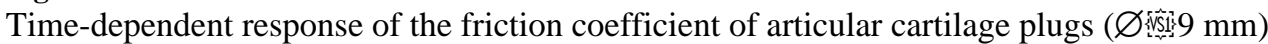
against a metal counterface, under a constant applied load of $30 \mathrm{~N}$, with reciprocal sliding of $\pm 25 \mathrm{~mm}$ at $4 \mathrm{~mm} / \mathrm{s}$, using either Ringer's solution or synovial fluid as the bathing solution. Reproduced from (Forster and Fisher, 1999) with permission. 


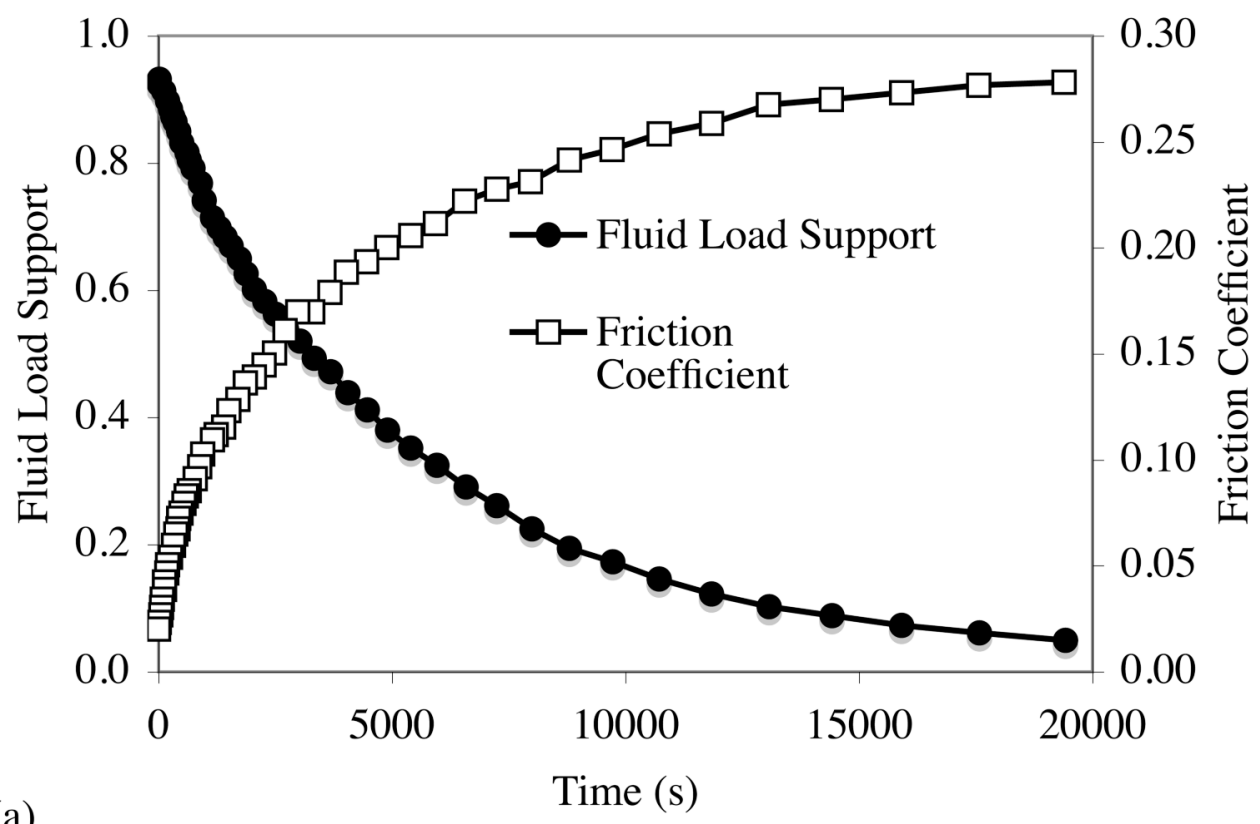

(a)

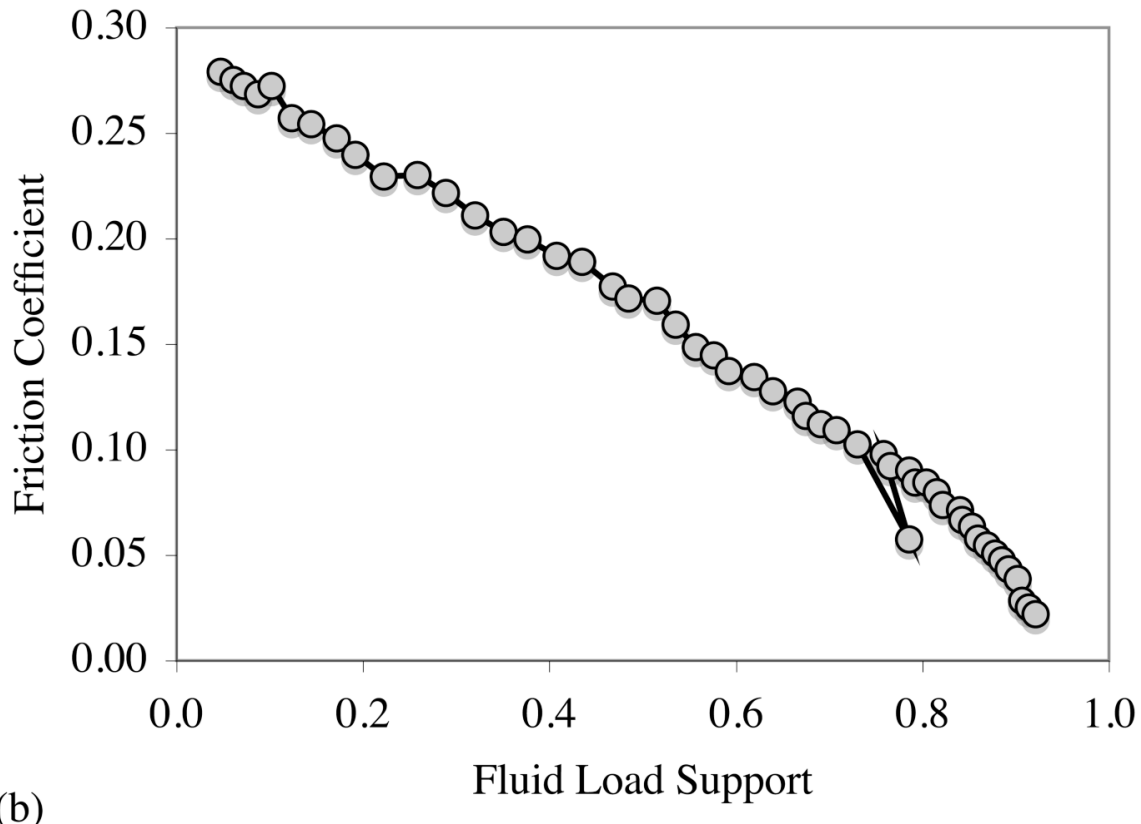

Fig. 3.

(a) Time-dependent response of the friction coefficient $\mu_{e f f}$ and interstitial fluid load support $W^{p} / W$ of articular cartilage plugs ( $\varnothing$ is $6 \mathrm{~mm}$ ) against glass, under a constant applied load of $4.5 \mathrm{~N}$, with reciprocal sliding of $\pm 2 \mathrm{~mm}$ at $1 \mathrm{~mm} / \mathrm{s}$. (b) A plot of $\mu_{\text {eff }}$ versus $W^{p} / W$ yields a linear variation, consistent with the model of Eq.(9). 


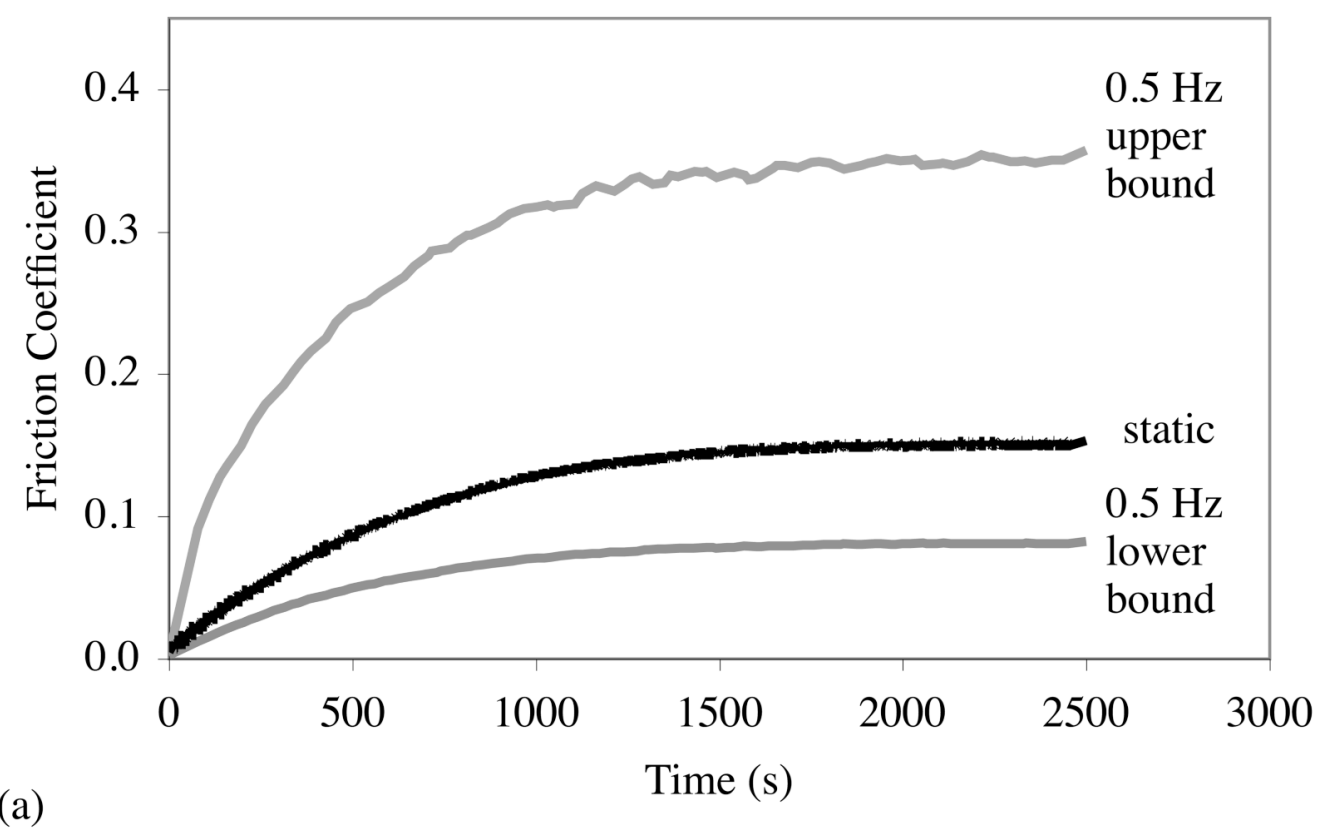

(a)

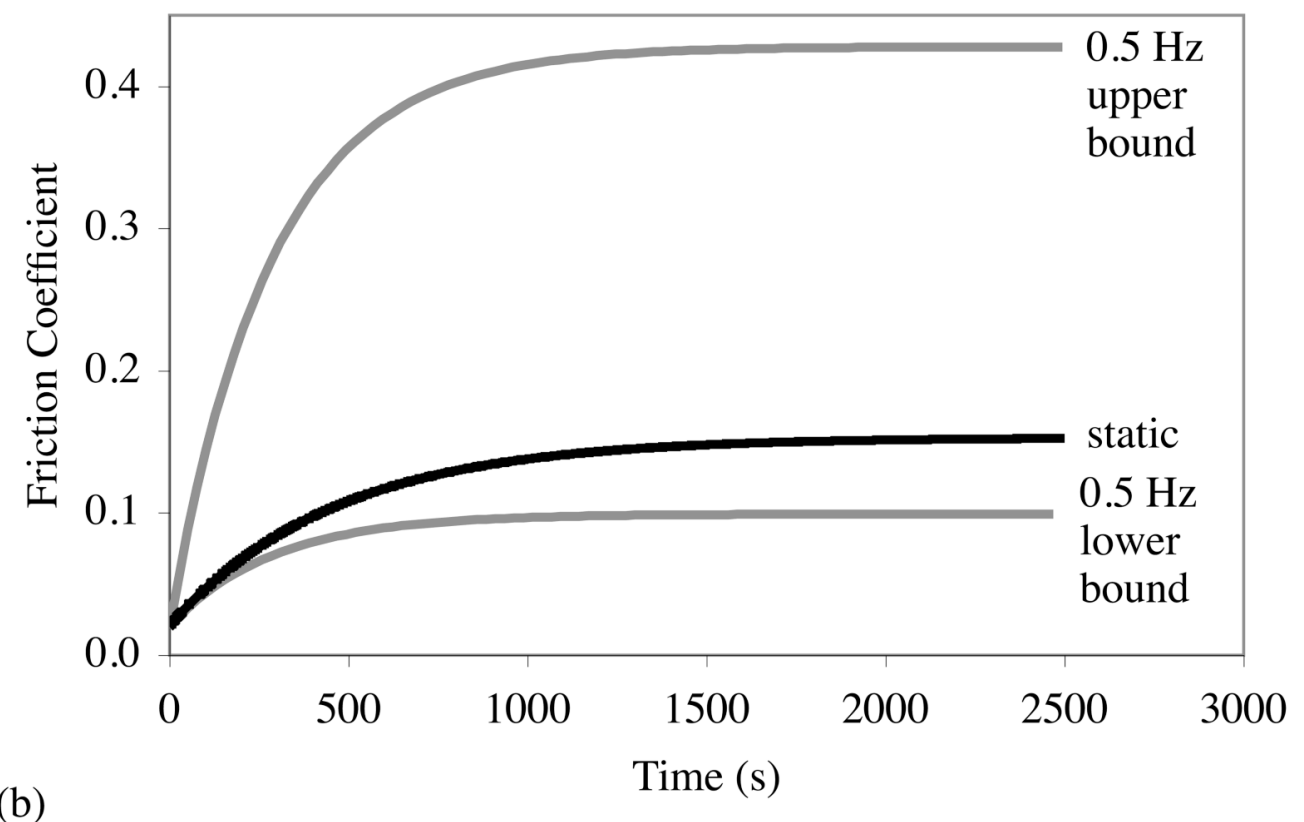

Fig. 4.

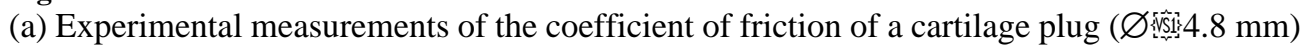
against glass, under a constant load of $13.4 \mathrm{~N}$, or a sinusoidal load varying from $4.5 \mathrm{~N}$ to 22.3 $\mathrm{N}$ at $0.5 \mathrm{~Hz}$, with reciprocal sliding of $\pm 4.5 \mathrm{~mm}$ at $1 \mathrm{~mm} / \mathrm{s}$. (b) Theoretical predictions of the friction coefficient, using Eq.(9) and the biphasic-CLE model (Soltz and Ateshian, 2000a) to estimate $W^{p} / W$. Reproduced from (Krishnan et al., 2005) with permission. 

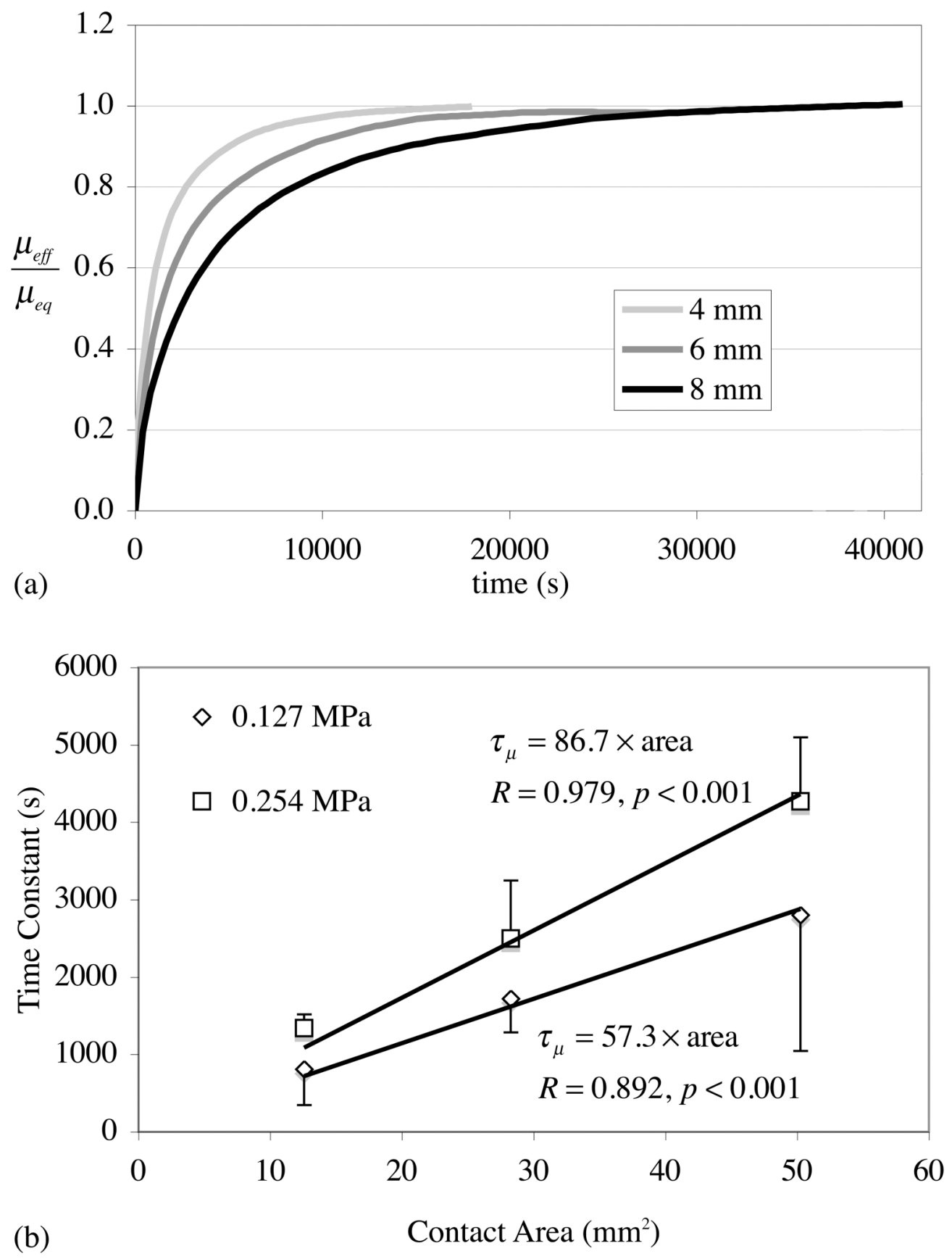

Fig. 5.

(a) Temporal response of the normalized friction coefficient $\left(\mu_{e f f} / \mu_{e q}\right)$ of a cartilage plug against glass, for various plug diameters $(\varnothing$ iss 4,6 and $8 \mathrm{~mm}$ ), under a constant applied stress of 0.25 $\mathrm{MPa}$, with reciprocal sliding of $\pm 4.5 \mathrm{~mm}$ at $1 \mathrm{~mm} / \mathrm{s}$. (b) A plot of the time constant $\tau_{\mu}$ for the rise of the friction coefficient versus the size of the contact area, for two different applied stresses, shows a linear response. Reproduced from (Carter et al., 2007) with permission. 


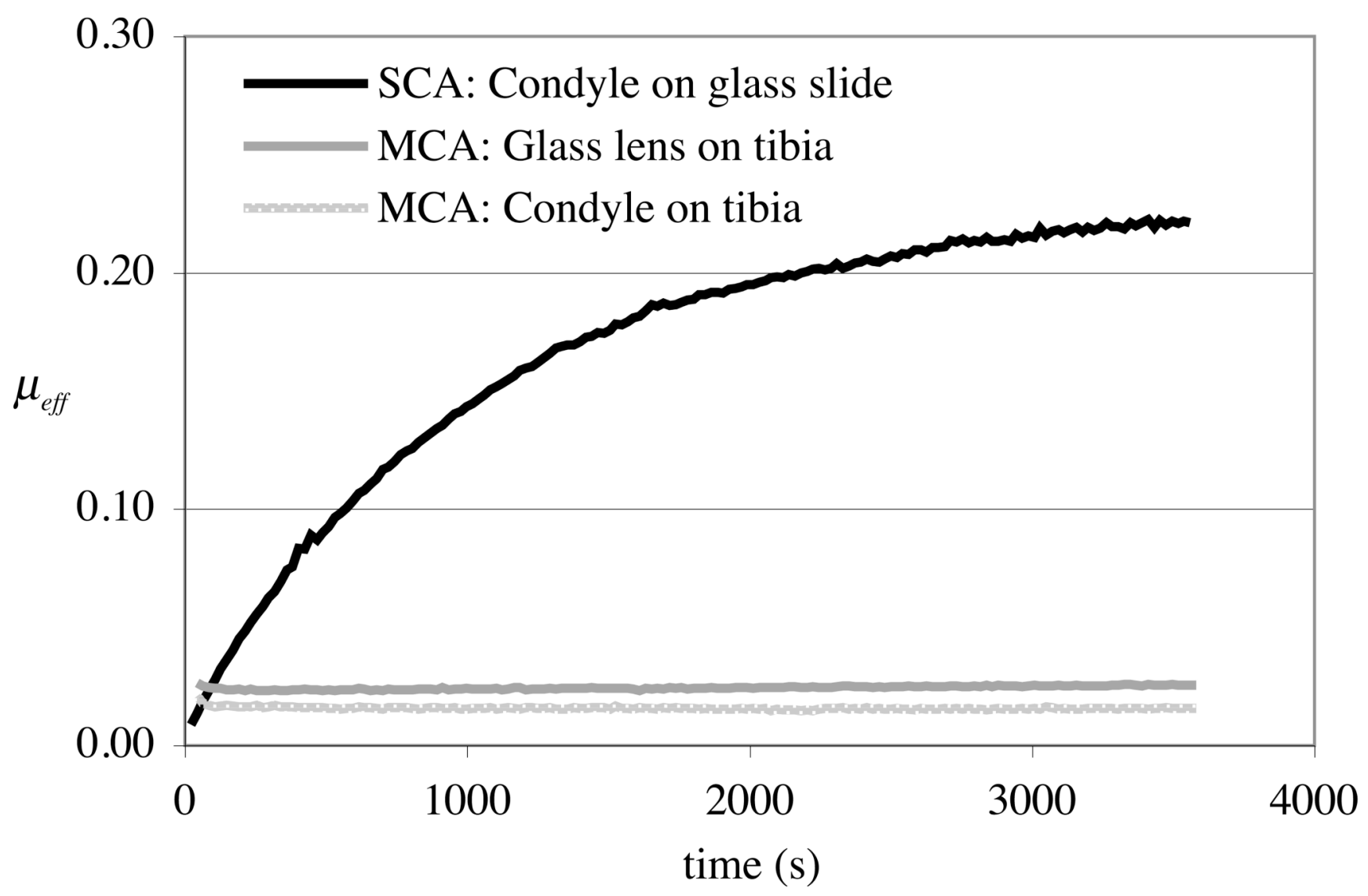

Fig. 6.

Comparison of the temporal response of the friction coefficient of cartilage in a loading configuration maintaining a stationary contact area on cartilage (SCA, bovine femoral condyle translating against glass) versus ones that promote a migrating contact area (MCA, glass lens translating over bovine tibial plateau, or femoral condyle translating against tibial plateau), under a constant applied load of $6.3 \mathrm{~N}$, with reciprocal sliding of $\pm 4 \mathrm{~mm}$ for SCA, $\pm 10 \mathrm{~mm}$ for $\mathrm{MCA}$, at $1 \mathrm{~mm} / \mathrm{s}$. The friction coefficient remains nearly constant under MCA, but increases to an equilibrium value under SCA. Reproduced from (Caligaris and Ateshian, 2008a) with permission. 


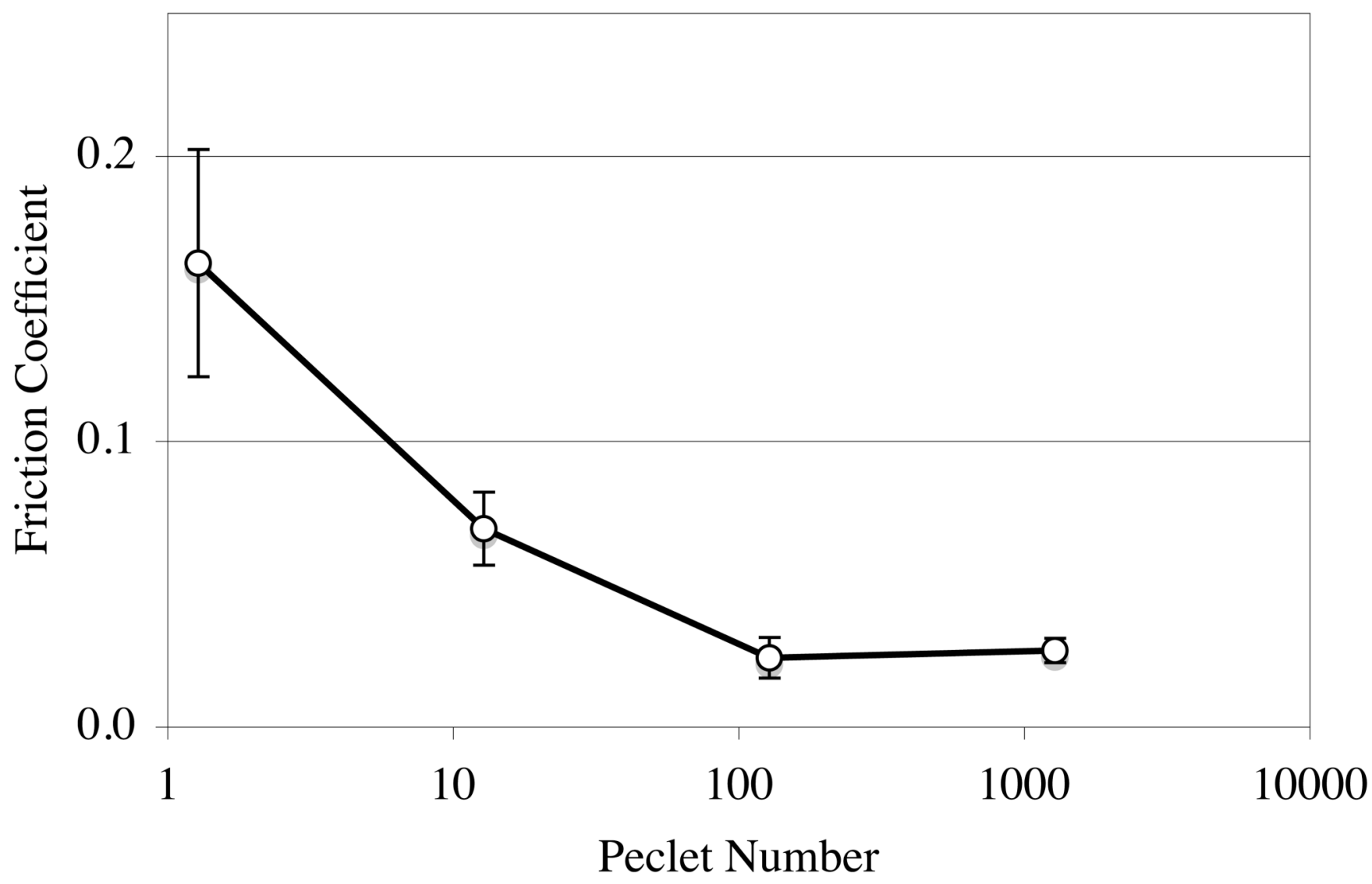

Fig. 7.

Friction coefficient between bovine femoral condyle and tibial plateau under the configuration of migrating contact area, under a constant applied load of $6.3 \mathrm{~N}$, with reciprocal sliding of $\pm 10 \mathrm{~mm}$, at four different sliding speeds $(0.005,0.05,0.5$ and $5 \mathrm{~mm} / \mathrm{s})$. The Peclet number $P_{e}=V a / H_{A} k$ was estimated using cartilage properties from the prior literature (Soltz and Ateshian, 2000a), and $a \sim 2 \mathrm{~mm}$. Reproduced from (Caligaris and Ateshian, 2008a) with permission. 


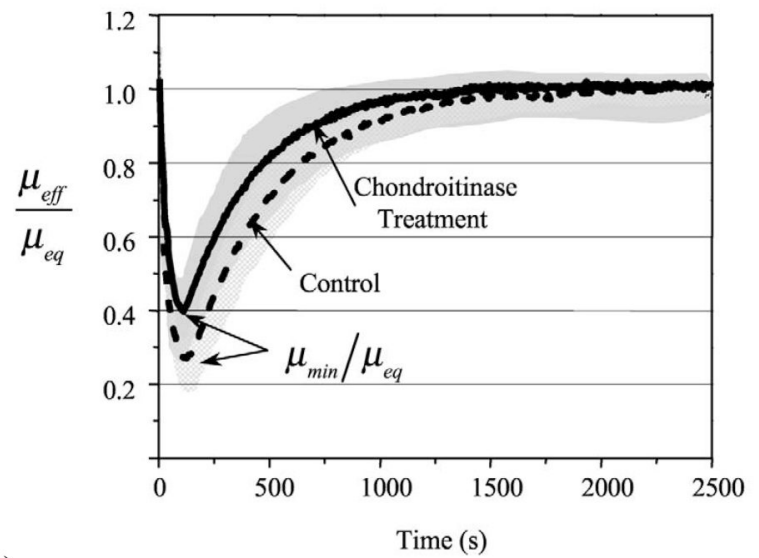

(a)

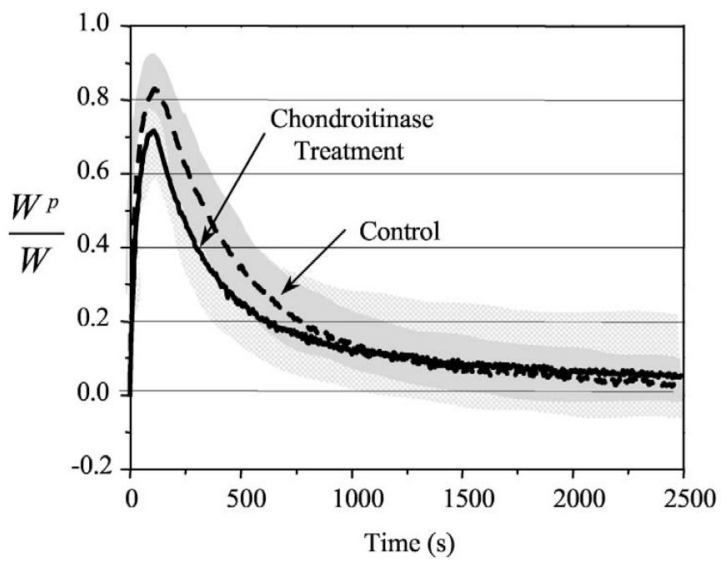

(b)

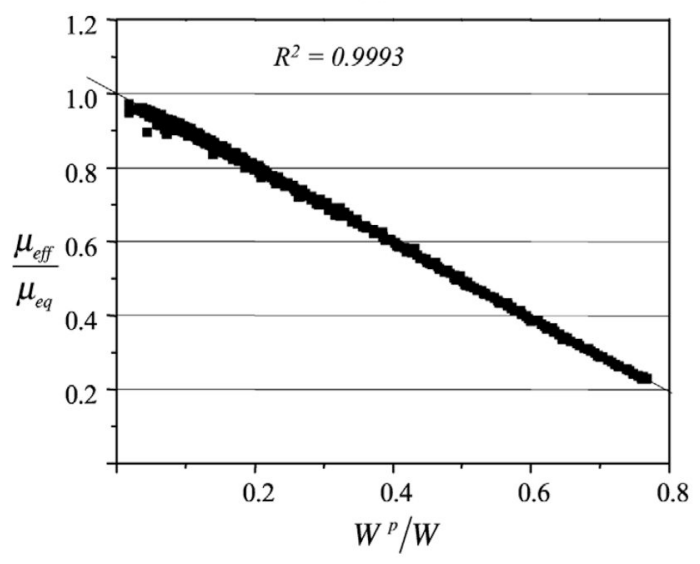

(c)

Fig. 8.

(a) Friction coefficient of control and chondroitinase-ABC digested cartilage plugs against glass, under a prescribed ramp-and-hold deformation profile producing a stress-relaxation response, with reciprocal sliding of $\pm 1.5 \mathrm{~mm}$ at $1 \mathrm{~mm} / \mathrm{s}$. A tare load was initially applied to the samples, which was allowed to equilibrate, explaining why $\mu_{e f f}=\mu_{e q}$ at the initiation of sliding. The ratio $\mu_{m i n} / \mu_{e q}$ was statistically higher in the digested cartilage group. (b) The interstitial fluid load support, estimated from the experimental load-deformation response using a relationship derived from the biphasic-CLE theory (Soltz and Ateshian, 2000a), exhibited a significantly lower peak in the digested group. (c) A parametric plot of $\mu_{e f f} / \mu_{e q}$ versus $W^{p} / W$ for a representative digested sample exhibits the characteristic linear response predicted from 
Eq. (9), demonstrating excellent agreement between theory and experiments. Reproduced from (Basalo et al., 2005) with permission. 